\title{
A simple area-based model for predicting airborne LiDAR first returns from stem diameter distributions: an example study in an uneven-aged, mixed temperate forest
}

Rebecca A. Spriggs, Mark C. Vanderwel, Trevor A. Jones, John P. Caspersen, and David A. Coomes

Version Post-Print/Accepted Manuscript

Citation Rebecca A. Spriggs, Mark C. Vanderwel, Trevor A. Jones, John P.

(published version) Caspersen, and David A. Coomes. A simple area-based model for predicting airborne LiDAR first returns from stem diameter distributions: an example study in an uneven-aged, mixed temperate forest. Canadian Journal of Forest Research. 45(10): 1338-1350. https://doi.org/10.1139/cjfr-2015-0018

Copyright / License 'Reprinted with permission. C 2015 Canadian Science Publishing or its licensors'.

How to cite TSpace items

Always cite the published version, so the author(s) will receive recognition through services that track citation counts, e.g. Scopus. If you need to cite the page number of the author manuscript from TSpace because you cannot access the published version, then cite the TSpace version in addition to the published version using the permanent URI (handle) found on the record page.

This article was made openly accessible by $U$ of $T$ Faculty. Please tell us how this access benefits you. Your story matters. 
1 A simple area-based model for predicting airborne LiDAR first

2 returns from stem diameter distributions: an example study in an

3 uneven aged, mixed temperate forest

4 Rebecca A. Spriggs, Mark C. Vanderwel, Trevor A. Jones, John P. Caspersen, and David A.

5 Coomes

6

7 R. A. Spriggs and D. A. Coomes. Department of Plant Sciences, University of Cambridge,

8 Cambridge, UK (ras212@cam.ac.uk; dac18@cam.ac.uk)

10 M. C. Vanderwel. Department of Biology, University of Regina, 3737 Wascana Parkway,

11 Regina, Regina, Saskatchewan, Canada.

12 (mark.vanderwel@ uregina.ca)

13 T. A. Jones. Ontario Ministry of Natural Resources and Forestry, Forest Research and

14 Monitoring Section, 1235 Queen Street East, Sault Ste. Marie, Ontario, Canada

$15 \quad$ (trevor.jones2@ontario.ca)

16 J. P. Caspersen. Faculty of Forestry, University of Toronto, 33 Willcocks Street, Toronto,

17 Ontario, Canada

$18 \quad$ (john.caspersen@utoronto.ca)

$19 *$ Corresponding authors: R. A. Spriggs and D. A. Coomes (e-mail: ras212@cam.ac.uk and

20 dac18@cam.ac.uk; phone: 01223333900). 
23 Abstract: Tree size distributions are of fundamental importance in ecology, forestry and global

24 change research. Airborne laser scanning (LiDAR) provides high-resolution information on

25 canopy structure and has great potential as a tool for mapping and monitoring tree stem diameter

26 distributions (SDDs) across forest landscapes. We present an area-based allometric model, with

27 three levels of species specificity, that links ground-based plot data to the height distribution of

28 LiDAR first returns $\left(\mathrm{HD}_{\mathrm{LIDAR}}\right)$, demonstrating the approach with surveys of a mixed, uneven-

29 aged forest in central Ontario, Canada. Our model translates stem diameters into estimates of

30 exposed crown area within $1 \mathrm{~m}$ height intervals; we then compared those estimates with $\mathrm{HD}_{\mathrm{LIDAR}}$

31 values. This basic approach gave reasonable goodness-of-fits (RMSE $=32 \%)$, but accuracy was

32 improved by adding mechanistic features to adjust crown shapes and crown permeability, and

33 allow for crown overlap and gaps $(\mathrm{RMSE}=17 \%)$. The model showed no bias in predicting

34 LiDAR returns in the mid-to-upper canopy (18-30 m), but tended to underestimate those from

35 the understory-level (2-8 $\mathrm{m})$ and overestimate returns from the ground and lower canopy (8-18

$36 \mathrm{~m})$. Our model represents an important step towards remote mapping of tree size distributions by

37 showing that LiDAR first returns can be accurately predicted from standard plot data by

38 considering a few fundamental canopy properties.

42 Key words: tree-size distribution, discrete-return LiDAR, mixed forest, allometry, canopy

43 model. 


\section{Introduction}

47 Tree stem diameter distributions (SDDs) are a fundamental property of forest structure and are

48 therefore integral to the productivity, water and nutrient cycles, carbon storage, wildlife habitat

49 suitability and disturbance risk of the forest (e.g. Parker et al., 1985; Kirschbaum, 1999; Sullivan

50 et al., 2013; Coomes and Allen, 2007; Lines et al., 2010). Forest managers rely on SDDs to

51 assess timber volumes and harvest yields (Scheller and Mladenoff 2004). In dynamic models of

52 global change responses, detailed forest structural information is valuable for setting initial

53 conditions, particularly when using individual-tree-based approaches (e.g. Köhler and Huth

54 1998; Scheller and Mladenoff 2004; Purves et al. 2008; Caspersen et al. 2011). Currently, SDDs

55 are routinely estimated by ground-based surveys, but these are expensive to conduct and based

56 on sampling rather than complete mapping of survey areas.

Airborne LiDAR (light detection and ranging) is a laser-based remote sensing technology

58 that produces high resolution point clouds of the locations where laser pulses have been reflected

59 from leaves, branches, stems and the ground (Lim et al. 2003). Airborne LiDAR is increasingly

60 used by foresters to measure biophysical properties of forests, including stand height, volume

61 and density, basal area, and leaf area index (e.g. Næsset 2002; Lim et al. 2003; Popescu, Wynne,

62 and Nelson 2003; Leeuwen and Nieuwenhuis 2010). Being able to map these properties over

63 entire landscapes is a significant advantage of using airborne LiDAR data with the majority of

64 work focusing on mapping aboveground carbon (e.g. Asner et al., 2012), biomass (e.g. Zhao et

65 al., 2009) or timber volume (e.g. Hill et al., 2014). Such properties are important to timber and

66 carbon accounting and can all be directly estimated from SDDs with some associated species

67 information, such as the proportion of conifers vs. broadleaves. Possessing information on the

68 underlying SDDs therefore offers another layer of detail and is particularly important for 
assessing current and future timber stocks. A number of different approaches have been proposed

70 for mapping SDDs, which we will go on to discuss. Our ultimate aim is to develop a novel

71 approach to map SDDs using airborne LiDAR, where stems are binned into user-defined

72 diameter classes at the scale of $2500 \mathrm{~m}^{2}$. In this paper, we explore the link between a forest

73 stand's stem size distributions and its airborne LiDAR returns; our emphasis is on establishing

74 the theoretical form of the relationship from basic principles.

75 Predictions of SDDs from airborne LiDAR can be organised into two distinct approaches:

76 area-based approaches (ABA; e.g. Maltamo et al. 2006; Breidenbach, Gläser, and Schmidt 2008;

77 Thomas et al. 2008; Jones, Woods, and Lim 2009; Valbuena et al. 2013) and individual tree

78 detection (ITD; e.g. Dalponte, Bruzzone, and Gianelle, 2011; Yao, Krzystek, and Heurich, 2012;

79 Vauhkonen and Mehtätalo, 2015). ABAs predominantly use traditional statistical relationships

80 with the best-fitting LiDAR metrics to estimate the parameters of a distribution describing the

81 stem diameters, such as the shape and scale parameters of a Weibull distribution (Thomas et al.,

82 2008; Jones et al., 2009). Breidenbach et al. (2008) predicted the shape and scale of a left and

83 right truncated Weibull from the first and third LiDAR height quartiles using a log link function.

84 The main benefits of the statistical methods are that they rely on standard forest inventory data

85 without any spatial information and are therefore relatively easily parameterised and applied in

86 new areas at the plot-level scale. The downside of using traditional statistical relationships is that

87 they are not necessarily intuitive; they are often based on whichever combination of metrics

88 offered the best fit to the data potentially resulting in over-fitted models. Many of these models

89 are not robust to extension to other forests where the metrics will be dependent on different

90 LiDAR acquisition properties (Næsset 2004), as well as offering questionable accuracy in un-

91 sampled regions of the forest (Vincent et al. 2012, Mitchard et al. 2014). 
ITD methods can make more informed predictions of SDDs based on scaling relationships

93 between a crown segmented from the point cloud and the expected associated stem diameter.

94 Dalponte et al. (2011) presented a method for inferring individual stem diameters and volumes

95 from crowns segmented using an algorithm developed by Hyyppä et al. (2001). The most

96 effective LiDAR metrics associated with the segmented crowns were used to predict the stem

97 diameters. Vauhkonen and Mehtätalo (2015) demonstrated how a transformation function can be

98 developed to map the cumulative distribution of segmented crown radii onto the cumulative

99 distribution of stem diameters; they emphasise that their method does not require mapped stems

100 and makes some compensation for inaccuracies in the delineation process. This method also

101 draws from the plot-level statistical methods as they selected the best-performing plot-level

102 LiDAR metric to predict the random plot-level effects to fine tune the transformation function.

103 Whilst ITD offers a promising alternative, ABA remains the approach favoured by foresters,

104 particularly in Scandinavia (Xu et al. 2014). ITD requires a minimum point density with most

105 studies reporting between 8-12 points $/ \mathrm{m}^{2}$, whereas ABA has been shown to be unaffected by

106 decreasing the point density to as low as 1 point $/ \mathrm{m}^{2}$ (Jakubowski et al. 2013), and, even at high

107 point densities, ITD struggles with crown overlap and cannot detect understory trees reliably.

108 Some progress has been made in combining the two approaches to take advantage of the

109 strengths of both methods; Xu et al. (2014) demonstrated how the SDD prediction made using

110 ITD and high density LiDAR can be combined with that made using an ABA and low density

111 LiDAR to improve the accuracy of the ABA estimates and reduce the bias of the ITD estimates.

112 Our ultimate aim is to offer an alternative approach to those listed above, which balances

113 the inclusion of realistic properties of the forest canopy with the simplicity to apply the model

114 across landscapes with low LiDAR point densities. First, we must develop the intermediate link 
115 model which bridges the gap between the SDD and the height distribution of LiDAR first returns

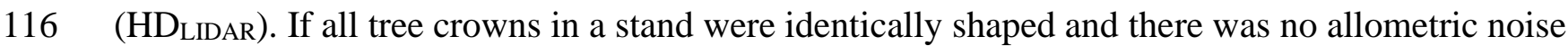

117 associated with the crown-stem diameter allometries, and if laser pulses were fired directly

118 downward and reflected off the upper surface of the forest canopy, then the link between size

119 distributions and LiDAR signals would be straightforward to describe. From this basic model,

120 we explore how adding additional complexity improves the predictions of the LiDAR return

121 distribution (HDPREDICT).

122 SDD - HD PREDICT models can be extremely detailed, as demonstrated in the ray-tracing

123 literature (e.g. Disney et al., 2010; Goodwin et al., 2007; Sun and Ranson, 2000) where the

124 interaction of each simulated laser pulse is predicted given a detailed representation of the forest

125 canopy. These models, such as the LiDAR Interception and Tree Environment (LITE) model

126 (Goodwin et al. 2007), allow us to explore the effect sensor properties have on the resultant

127 LiDAR data. For our purposes, we require a model that falls between these two extremes, but

128 which additional features should be included in our basic model?

129 Within a given plot, our basic model predicts the crowns from non-spatial diameter at 130 breast height (dbh) measurements based on a single fixed allometry. The predicted crown areas

131 within $1 \mathrm{~m}$ height intervals are summed and the exposed canopy area within each interval is used

132 to generate the HDPREDICT, which we compare with the HDLIDAR. In this way, we are considering

133 the individual trees, as in ITD methods, but not explicitly. As previously discussed, one of the

134 limitations of this method is that crown overlap and overtopping reduces the exposed crown area

135 (Vauhkonen and Mehtätalo 2015), so this is the first feature that should be incorporated.

136 Drawing from the ray-tracing methods, the fundamental canopy property determining the

137 behaviour of the LiDAR pulse is the distribution of foliage (Goodwin et al. 2007). Without 
138 spatial information and maintaining an ABA, we approximate the distribution of foliage

139 important to predicting first returns by three additional features: gap fraction, more detailed

140 crown shapes and crown permeability (Jochem et al. 2010). The combination of these features

141 should help to refine the predicted area of foliage at given heights.

142 Here, we develop the link between the SDD and the HDPREDICT which operates at the plot-

143 level, yet includes key properties of the forest canopy; the proposed benefits of this method are

144 that it is simple, requiring only standard forest inventory data, low density LiDAR and low

145 computational power, it is intuitive, therefore can plausibly be recalibrated to other similar

146 forests, and has been developed on a relatively complex forest type. A large proportion of the

147 research in this area is based in alpine, mountain or boreal forests which are therefore largely

148 comprised of coniferous species. We test the model on an uneven aged, mixed conifer-broadleaf

149 forest of central Ontario, Canada, which therefore has a relatively complex structure as compared

150 with many that are used in the literature.

151 We will address two research questions: 1) is a single allometry sufficient or is more

152 species information required? 2) How does each feature independently improve the basic model

153 (gap fraction, crown shape refinement, canopy permeability and crown overlap)? In the

154 discussion, we will discuss the feasibility of using this approach to map SDDs.

156 Materials and methods

157 Study area

158 The Haliburton Forest and Wildlife Reserve is a 32,000 ha privately owned property located in

159 the Great Lakes - St. Lawrence Forest Region of central Ontario, Canada $\left(45^{\circ} 13^{\prime} \mathrm{N}, 78^{\circ} 35^{\prime} \mathrm{W}\right)$.

160 The forest grows on undulating terrain (ranging from approximately $400-500 \mathrm{~m}$ above sea 
161 level). Monthly temperatures range from an average of $-7.5 \pm 3.2{ }^{\circ} \mathrm{C}$ in the winter months to 17.8

$162 \pm 1.5^{\circ} \mathrm{C}$ in the summer months. Average monthly precipitation is $84 \pm 9.5 \mathrm{~mm}$ (Environment

163 Canada 2012). The forest is a mixture of broadleaf and conifers species; it is dominated by sugar

164 maple (Acer saccharum Marsh), but several other species are common, including eastern

165 hemlock (Tsuga canadensis (L.) Carrière), American beech (Fagus grandifolia Ehrh.), red maple

166 (Acer rubrum L.), balsam fir (Abies balsamea (L.) Mill.) and yellow birch (Betula alleghaniensis

167 Britt.). Across the region, forests are extensively managed for timber using selection silviculture,

168 but there are small patches of unmanaged old-growth stands where the terrain is unsuitable for

169 harvesting machinery. Natural disturbances include both small-scale gap-disturbances and rare

170 large-scale wind events (Vanderwel et al. 2008).

\section{Inventory plot and LiDAR datasets}

173 The ground plot data were comprised of 154 circular plots each with a radius of $28.2 \mathrm{~m}$

174 corresponding to an area of $2500 \mathrm{~m}^{2}$ (Fig. 1). We selected the plot locations using a stratified

175 sampling design: the forest was classified into seven different ecotypes using overstory species

176 composition and structure, soil type and the moisture regime and then these were further

177 subdivided into six levels of canopy openness determined by eye from aerial imagery. We

178 randomly selected plots so that at least two plots represented each of the 42 possible

179 combinations. Within each plot, all trees with a dbh greater than $8 \mathrm{~cm}$ were identified to species

180 and the dbh measured. The centre points of each plot were georeferenced to within $1 \mathrm{~m}$ using a

181 differential GPS. See Table S.1 for additional plot details.

182 Discrete airborne LiDAR data were collected in August 2009 using a Cessna Turbo 206

183 Stationair aircraft outfitted with an Optech ALTM 3100 LiDAR four-pass system which is 
184 capable of recording up to 100,000 measurements per second with potentially four returns per

185 pulse, each with an associated intensity. The system was flown at an altitude of $1500 \mathrm{~m}$,

186 therefore achieving a pulse repetition frequency of $70 \mathrm{kHz}$, with a pass overlap of $30 \%$ (see

187 Table S.1 for flight specifications and definitions of terms). The average first return point density

188 was 2 points per $\mathrm{m}^{2}$. The precisely geolocated points making up the point cloud were run through

189 a classification routine to provide an initial surface model (i.e. isolating the points associated

190 with the ground or close to the ground). The initial surface model was then smoothed using

191 Optimal Geomatics' proprietary methods to determine a digital elevation model (DEM), which

192 was checked using control and validation points across the area (horizontal tolerance of less than

$1930.75 \mathrm{~m}$ and consolidated vertical accuracy of $0.20 \mathrm{~m}$ ). A triangular irregular network (TIN) was

194 constructed from the points classified as ground returns which then provided a $\mathrm{z}$-coordinate

195 associated with the ground for every return; all returns were then converted from the height

196 above sea level to the height above the ground by subtracting these ground z-coordinates. We

197 used only the first return data in our analyses to increase the generality and interpretability of our

198 model (Næsset 2004). We clipped the LiDAR data corresponding to each inventoried plot from

199 the wall-to-wall dataset using ArcGIS 10 and then the first returns were sorted into $1 \mathrm{~m}$ vertical

200 height intervals above the ground.

202 Description of the basic allometry-based model

203 Using the forest inventory data, we constructed a model of the size and shape of all of the crowns

204 (Fig. 2a) in the plot using pre-existing allometric equations (Purves, Lichstein, and Pacala 2007;

205 Caspersen et al. 2011 - hereby referred to as the published allometric functions). This model was

206 used to estimate the proportion of exposed canopy area within $1 \mathrm{~m}$ height intervals (ECA, the 
canopy surface which is exposed to laser pulses; Fig. 2b), thereby transforming dbh

208 measurements into a prediction of the height distribution of the ECA. The premise of this basic

209 model is that LiDAR first returns backscatter off exposed canopy, so the predicted proportion of

210 ECA within each $1 \mathrm{~m}$ height interval is assumed to be directly proportional to the observed

211 distribution of LiDAR first returns (HD LIDAR $_{\text {. Note }}$ that this model makes use of published

212 allometric functions, but does not contain any tuneable parameters.

213 The model requires stem diameter information and so we then explored how adding

214 species information improves the predictions. We present three versions of the model: 1) using a

215 single allometry for all species, 2) using two allometries (one for conifers and one for

216 broadleaves) and 3) using species-specific allometries for the eight most prevalent species plus a

217 generic conifer and broadleaf allometry for all other species.

218 The crown components predicted from dbh were tree height, crown depth, maximum

219 crown radius and crown shape (Table S.1-Table S.3), from which the exposed crown area within

220 height tiers could be calculated for every tree within the plot. Vertical heights, $h$, are sorted into

$2211 \mathrm{~m}$ height tiers denoted as $[h, h+1)$; this is equivalent to $h \leq x<h+1$ where $\mathrm{x}$ is some

222 height falling within the interval. Within each height tier, the exposed area of all crowns was

223 summed $\left(E C A_{[h, h+1)}\right)$, and then transformed to a proportion of the total canopy area

$224\left(\sum_{i=0}^{\infty} E C A_{[i, i+1)}\right.$; where $i$ denotes the $1 \mathrm{~m}$ heights and $h_{\max }$ is the maximum height predicted in

225 the plot rounded up to the nearest meter) as follows:

$226 \quad(1)$

$$
\left.H D_{P R E D I C T}^{B A S I C}, h+1\right)=\frac{E C A_{[h, h+1)}}{\sum_{i=0}^{h_{\max }} E C A_{[i, i+1)}}
$$


229 al. 2011) was used in the single allometry model and also for the generic broadleaf allometry

230 used in the two allometry and species-specific model versions, since sugar maples are the

231 dominant species within the study area. The generic conifer allometry was obtained by re-fitting

232 the allometries to simulated data aggregated from species-specific predictions of each remaining

233 coniferous species weighted according to species abundance (Purves et al. 2007, Caspersen et al.

234 2011). In the species-specific version of the model, allometries for the eight most abundant

235 species (Purves et al. 2007, Caspersen et al. 2011) were used in the calculations of $E C A_{[h, h+1)}$

236 and $\sum_{i=0}^{h_{\max }} E C A_{[i, i+1)}$; these species accounted for over $80 \%$ of the basal area represented in the

237 stratified plot inventory. For the remaining species, the generic broadleaf and conifer allometries

238 were used. See Table S.1 for allometric functions and Table S.2 and Table S.3 for associated

239 parameter values.

240 Our aim was, ultimately, to develop a simple model which offers the best possible

241 prediction (HDPREDICT) of the observed distribution of LiDAR first returns. The resultant model

242 provides the intermediate link between SDDs and the HDLIDAR which is necessary to generate a

243 suite of height distribution predictions quickly from theoretical SDDs. The model thus offers a

244 tool for matching any given HDLIDAR for a similar forest to a most likely SDD; we expand on this

245 further in the discussion (Fig. 3). We consequently needed to assess the performance of the basic

246 model, where performance was measured by a reduction in the difference between the observed

247 and predicted distributions (HD LIDAR - HDPREDICT), and then we considered how the additional

248 features improved model performance. 
251 The basic model assumed that published crown allometries were accurate, that LiDAR first-

252 returns were backscattered off the outer shell of the forest canopy (i.e. that crowns are

253 impermeable), that there were no gaps in the canopy, and that individual trees had non-

254 overlapping crowns. Since we made no spatial considerations, there is an underlying assumption

255 that tree crowns organise themselves in space to minimise overlap (the perfect plasticity

256 approximation of Purves et al. 2008) whereas in reality there may be considerable overlap in

257 some places and gaps in others. In the following section, we describe how the basic model was

258 refined in order to relax these assumptions. The parameters of the functions used to refine the

259 basic model were estimated from a 114 plot training dataset; any improvement in fit was then

260 assessed using the remaining 40 plot test dataset.

261 Allowing for gaps in the forest canopies: The proportion of pulses reflected off the ground

262 (ground returns, $\mathrm{p}_{0}$ ) was assumed to be exponentially related to the total canopy area of a stand:

263

$$
p_{0}=\exp \left(-\alpha \cdot \frac{\sum_{i=0}^{h_{\max }} E C A_{[i, i+1)}}{P A}\right)
$$

264 Where $\alpha$ is a parameter and the second component in the exponential is the total canopy area (i.e.

265 the sum of the ECA within all height tiers) divided by the plot area (PA; see Table S.4 for all

266 parameter definitions). Given the estimated $\mathrm{p}_{0}$, the predicted proportions of first returns made by

267 the basic model were scaled to give an HDPREDICT which sums to 1.

268 Adjusting crown shapes: To account for the often sparse datasets of crown shape measurements

269 and that the crowns represented by the LiDAR first returns may differ from the allometric

270 predictions (Piboule et al. 2005), we fitted a new crown shape parameter $(\beta)$ for all allometries

271 used in each version of the model (see supplementary material; eqn. (S. 1)). All other parameters

272 in the allometry were unaltered. The crown shape parameter controls the curvature of the crown 
273 ranging from convex $(\beta<1)$ to linear $(\beta=1)$ to concave $(\beta>1)$; this determines how the

274 crown radius decreases from the base of the crown to the peak.

275 Allowing tree crowns to be semi-permeable: LiDAR pulses may penetrate into a tree crown

276 before being backscattered at sufficient intensity to register a return in the laser scanner. Hence,

277 first returns are not necessarily from the outer shell of the crown (Gaveau and Hill 2003,

278 Chasmer et al. 2006). The following crown permeability (or crown transparency) parameter $(\varphi)$

279 relaxes the assumption that first returns scatter off the outer shell by allowing a proportion, given

280 by $\varphi$, to pass through the crown from the height interval above:

$281 \quad(3)$

$$
H D_{P R E D I C T}^{P E R M}[h, h+1)=H D_{P R E D I C T}^{B A S I C}[h, h+1) \cdot(1-\varphi)+H D_{P R E D I C T}^{B A S I C}[h+1, h+2) \cdot \varphi
$$

282 For example, if the crown were a cylinder, then $(1-\varphi)$ gives the proportion of the crown

283 area that would be recorded from the height interval in which the top of the tree falls, and $\varphi$

284 gives the proportion that would be recorded from the interval below.

285 Accommodating overlap between tree crowns: There is a strong likelihood that small trees

286 within a stand are overtopped or overlapped by neighbours and so are not apparent in the LiDAR

287 first-return signal. We assumed that the probability of crowns in a given height tier being

288 exposed to LiDAR depends on the canopy area within higher tiers. We incorporated this effect as

289 a crown overlap correction factor $\left(\theta_{[h, h+1)}\right)$ determined by a negative exponential of the

290 proportional cumulative canopy area at a particular height where $\gamma$ controls the shape of the

291 exponential; cumulative canopy area refers to the total ECA above this given height.

292

$$
\theta_{[h, h+1)}=\exp \left(-\gamma \cdot \frac{\sum_{i=h+1}^{h_{\max }} E C A_{[i, i+1)}}{P A}\right)
$$

293 Combining all refinements into the full model: The crown permeability and crown overlap

294 features can be combined into the following: 
296

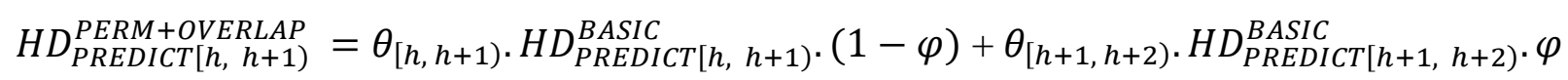
crown permeability and crown overlap is therefore given by:

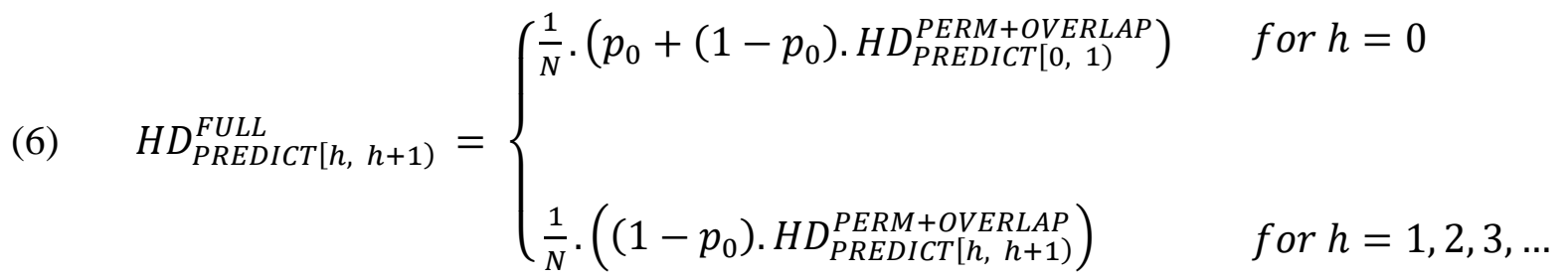

where $\mathrm{N}$ is a normalisation constant calculated such that $\sum_{h=0}^{h_{\max }} \operatorname{HD} D_{P R E D I C T}^{\text {FULL }[h+1)}=1$

302 The HDPREDICT of the basic model $\left(H D_{P R E D I C T}^{B A S I C}[h+1)\right)$ is defined in eq. 1 , the proportion of

303 ground returns $\left(\mathrm{p}_{0}\right)$ is defined in eq. 2 , crown permeability $(\varphi)$ in eq. 3, crown overlap $\left(\theta_{[h, h+1)}\right)$

304 in eq. 4 and the combination of the two $\left(H D_{P R E D I C T[h, h+1)}^{P E R M+O V E R L P}\right)$ in eq. 5.

306 predict SDDs.

\section{$308 \quad$ Model fitting}

309 Building on the basic model, which has no tuneable parameters, we added the four features

310 detailed above to show how each influenced model performance in each of the three versions of

311 the basic model. All four features were then combined in the full model. We estimated the

312 parameter values that minimised the difference between HDPREDICT and HDLIDAR in the training

313 plots, and measured model performance using the test plots. 
We used a Markov Chain Monte Carlo (MCMC) algorithm, implemented in the Filzbach

315 C\# library (Purves and Lyutsarev 2011), to estimate the parameters in the model features

316 described above. In each case, the log-likelihood was calculated by assuming that the probability

317 density function of (HDLIDAR - HDPREDICT) was normally distributed with a mean zero and a

318 standard deviation $\sigma$. We used uninformative priors, and sampled parameters uniformly between

319 upper and lower bounds that were chosen to be algebraically sensible or biologically reasonable.

320 For each version of the model, we ran 3 replicate chains of 9,000 iterations each and a burn-in of

3211,000 iterations, except for the full model where each chain comprised of 35,000 iterations, with

322 a burn-in of 5,000 iterations, to allow for the greater number of parameters. All models

323 comfortably converged within the allotted number of iterations. We retrieved estimates for the

324 posterior means and 95\% credible intervals of all parameters, and used a deviance information

325 criterion (DIC) to compare support for the models. Model performance was compared by

326 predicting HDPREDICT for the 40 plots set aside for testing purposes, and then calculating the

327 RMSE for each of the test plots by plotting the HDPREDICT against the corresponding HD

329 Results

330 Model performance

331 The full model with all of the features included was the best supported statistically (lowest DIC

332 and mean RMSE) in each of the three versions of the model (Table 1). Overall, the full model

333 with the species-specific allometries offered the lowest DIC, but the two allometry version of the

334 full model predicted the distribution of LiDAR first returns for the test plots (mean RMSE =

$3350.0196 \pm 0.0075)$ equivalently well as the species-specific full model (mean RMSE $=0.0196 \pm$

336 0.0074). When the predictions for each version of the full model were averaged over all of the 
337 test plots (Fig. 4), the one-allometry model offered a poorer fit than the two more complex

338 versions. When focusing on the two- and ten-allometry predictions, the model is seen to capture

339 the distribution of returns from the top of the canopy and ground, although it slightly over-

340 predicts frequencies in the mid-height range $(\sim 15 \mathrm{~m})$ and under-predicts at lower heights. The

341 performance of the full species-specific (ten-allometry) model is interpreted at the plot level in

342 Fig. 5 to show examples from the full range of predictions. The RMSE statistics, across all test

343 plots, for the full model indicated a greatly improved fit compared with the basic model in all

344 versions of the model (Table 1; Fig. 6). The RMSEs in the full model were clustered more

345 closely to zero than all of the other models with relatively little spread; this was also supported

346 by the DIC. The disparity in model performance of the different levels of allometric complexity

347 is greatly decreased in the full model compared with the basic model with a much smaller

348 difference in mean RMSE between the one and ten allometry models (basic: 0.0082; full:

$3490.0012)$.

\section{Individual performance of model features}

351 Each feature in our model led to improvements in model fit, based on comparisons with the 352 independent test dataset, compared to the basic model (Table 1; Fig. 6), with the exception of the 353 crown overlap feature. The crown shape adjustment term led to the greatest improvement in fit 354 almost halving the mean RMSE in the single allometry model, whilst gap fraction only decreased 355 the mean RMSE slightly and crown overlap had no effect at all when included independently in 356 the basic model (Table 1 and inset of Fig. 6).

357 Gap fraction: The proportion of ground returns was observed to decrease exponentially in 358 relation to the total canopy area of the forest stands (Fig. 7a). Returns are still reaching the 359 ground when the crown area exceeds the plot area (about 10\% when the total crown area is equal 
360 to the plot area), but only about $2 \%$ of returns come off the ground when the total crown area

361 exceeds 1.5 times the plot area.

362 Crown taper: Crown shapes generated to maximize similarity between HDLIDAR and HDPREDICT

363 were different from the shapes expected from published allometries for six of the ten species

364 groups (Fig. 8; parameters in Table S.5 ). Balsam fir, ironwood and red maple were predicted to

365 be more concave (conical) than the original crown shape estimates ( $\beta$ increased), whilst beech,

366 hemlock and yellow birch were predicted to be more convex (less conical; $\beta$ decreased). The

367 crown shapes for sugar maple, white spruce, broadleaf and conifer changed very little from the

368 original estimates (Fig. 8 compares the original crown shapes to the new crown shapes); these

369 were all originally parameterised from large sample sizes. With the exception of balsam fir, the

370 remaining species were originally parameterised using relatively small sample sizes given the

371 study area was dominated by sugar maples at a prevalence ranging from $63-82 \%$ across different

372 size classes (Caspersen et al. 2011).

373 Crown permeability: The tree crowns were estimated to be $65 \%$ permeable within a $1 \mathrm{~m}$ interval

374 to LiDAR first returns just entering the crown in the species-specific full model (Fig. 7b); this

375 value was approximately the same as the estimated permeability when no other features were

376 incorporated into the model. Crown permeability was the second most influential feature, after

377 crown taper, when added independently to the basic model (inset of Fig. 6).

378 Crown overlap: The crown overlap feature was not useful in improving the similarity between

379 HD $_{\text {LIDAR }}$ and HD PREDICT when considered alone (inset of Fig. 6), with the crown overlap function

380 being fitted as a horizontal line at one. When considered in the full model, the crown overlap

381 function proved to be important in increasing the performance of the model (DIC of the full

382 single allometry model with crown overlap: -19 057; DIC of the full single allometry model 
383 without crown overlap: -18 759). In the full model, crown overlap will tend to increase from the

384 top of the canopy to the base, which is represented in Fig. 7c. Deeper into the canopy, the

385 cumulative canopy area will become increasingly large and therefore more of the ECA will be

386 shaded or overlapped by a neighbouring crown; the overlap correction factor serves to decrease

387 the ECA as the cumulative canopy area increases. When the cumulative canopy area is equal to

388 the plot area, approximately $55 \%$ of the ECA is recorded by the LiDAR first returns and

389 therefore $45 \%$ of the ECA is predicted to be overlapped or overtopped. In a dense plot, we

390 expect there to be a greater degree of crown overlap and therefore the more severe penalties in

391 Fig. 7c would be reached, whereas the ECA in sparser plots would be less severely penalised

392 overall due to a lower expected degree of overlap amongst crowns.

393

394 Discussion

395 Airborne LiDAR provides an efficient means of obtaining high-resolution information on forest

396 structure over forested landscapes, but it is not at present being used to predict tree size

397 distributions by foresters or ecologists. This paper takes an important step towards developing an

398 approach for mapping size-distributions remotely, by demonstrating the close links between the

399 height distribution of LiDAR first returns and SDDs measured in inventory plots. A model based

400 solely on the basic geometry of tree crowns was not very accurate, but adding a few tuneable

401 parameters to accommodate for gap fraction, variable crown form, crown permeability and

402 crown overlap provided enough flexibility to achieve a great improvement in goodness-of-fit.

403 Here we discuss these tuneable features in more detail, before discussing how the approach could

404 be used to map size distributions from aircraft.

405 
407 We found predictions based on published crown-shape functions were not sufficient for

408 replicating the crowns as captured by LiDAR, and that including a tuneable parameter was

409 essential in order for accuracy. Refining the overall crown shape was more important than

410 adding detailed information about crown allometries of individual species: a single crown shape

411 with a tuneable parameter was better supported statistically than having different allometries not

412 fitted to the LiDAR data for each of the ten species (Table 1). Having an accurate knowledge of

413 crown shape has been shown to be important for predicting LiDAR pulse height distributions

414 (Nelson 1997, Sun and Ranson 2000). Van Leeuwen, Coops, and Wulder (2010) developed an

415 approach for fitting together simple geometric shapes to provide the best approximation of a

416 given canopy height model and van Leeuwen et al. (2013) used a flexible cone shape to fit to

417 ground LiDAR data of a coniferous forest. Our findings support the use of simple shapes, since

418 we found no discernible difference between the predictive accuracy of a model based on only

419 two allometries compared with models using ten.

\section{Crown permeability, overlap and gap fraction}

422 Crown permeability to LiDAR pulses and crown overlap influenced how canopies were

423 manifested in the point cloud ( $\mathrm{Li}$ et al. 2012) and thus proved an important property to capture in

424 the model. The basic model assumes that LiDAR pulses are reflected off the outer shell of the

425 canopy whereas in reality some LiDAR pulses penetrate into the crown before being first

426 reflected (Gaveau and Hill 2003, Maltamo et al. 2004). For example, Disney et al. (2010)

427 estimated that true canopy height was significantly underestimated $(\sim 4 \%$ for broadleaves and $\sim$ 
$16 \%$ for conifers) as a result of pulse penetration. Our model predicts $65 \%$ of first returns will be

429 reflected within $1 \mathrm{~m}$ from where they entered the crown suggesting there is a high degree of

430 permeation through the crown. Penetration of light is likely to vary with tree size (because leaf

431 area index is size dependent; Nock, Caspersen, and Thomas 2008) and with the degree of foliage

432 clumping (Goodwin et al. 2007). Since our model considers the stand as a whole, as opposed to

433 considering individual trees, these effects might be averaged out, particularly in the full model

434 where the permeability feature will have some trade-off with the crown overlap correction factor.

The crown overlap function was found to be useful when used in combination with the

436 other features, but redundant when used alone in the basic model. The interplay with the refined

437 crowns, predicted gaps and permeable foliage meant crown overlap was then an important

438 feature to include. The crowns overlap more the deeper into the canopy they are with the degree

439 of overlap determined by the canopy area overhead; a sparsely populated plot will be minimally

440 penalised, even close to the ground, since the cumulative crown area will be low relative to the

441 plot area. Competition among crowns in plots with high stem densities has a major influence on

442 crown form (Canham et al. 2004, Lines et al. 2010, Coomes et al. 2011). The crowns in the basic

443 model were fixed, based on dbh and species, but the crown overlap function serves to adapt these

444 fixed predictions to lower the probability of a return being made when the environment

445 effectively becomes "more competitive". Whether it is the case that two crowns are simply

446 overlapping or that one of the crowns has dominated and the other has dropped its foliage in

447 response (Garber and Maguire 2005; Purves, Lichstein, and Pacala 2007), the ultimate effect on

448 LiDAR returns is the same. Goodwin, Coops, and Culvenor (2007) noted that the differing

449 crown shapes in the field will also cause returns to be made from regions other than the fixed

450 predicted exposed area. Our model does not explicitly measure at which point a crown will 
451 become overtopped, nor which tree is overtopped by the other, but the overlap correction factor

452 assigns a probability that is shared amongst all trees at a given height that they have been

453 overtopped. The overall degree of overlap in a plot is determined by the canopy area and is

454 therefore interlinked with the gap fraction.

455 Gap fraction has important influences on LiDAR return distributions, but proved difficult

456 to capture without any explicit consideration of the location of trees within plots. Our attempts to

457 model gap fraction using the total crown area was not universally successful, because some plots

458 contained waterlogged patches within which tree cover was discontinuous (RS, personal

459 observation) and these patches produced many more ground returns than predicted by our

460 canopy-cover function (see Bugmann 2001 for a discussion of the link between gap fraction and

461 canopy cover). An approach, not explored here, is to use the LiDAR point cloud to identify gaps

462 and use this information in the predictive models (Koukoulas and Blackburn 2004, Gaulton and

463 Malthus 2010).

464 It is clear that predicting LiDAR height-return distributions from inventory data requires

465 an understanding of canopy structure and the interaction of LiDAR pulses with the canopy. How

466 can we use this link to make informative predictions of SDDs across large scales?

468 Mapping SDDs from LiDAR data

469 Using a mechanistic approach, we have shown close links between SDDs and HDLIDAR,

470 suggesting that it should be possible to map diameter distributions, using airborne LiDAR. In

471 principle, the LiDAR dataset could be carved up into plot-sized tiles, and the most likely tree size

472 structure of each tile inferred using the link function developed here (Fig. 3): the HDLIDAR of a

473 given tile would be calculated, and the most likely size structure would be obtained by predicting 
474 the HDLIDAR for a particular theoretical SDD, comparing that prediction with the HDLIDAR, and

475 then continuing to search through many theoretical SDDs until a close match is found between

476 observed and predicted HD LIDAR (see Fig. S.1). Given the accuracy of our model and the

477 likelihood that multiple SDDs will produce the same HDLIDAR, our model will be able to produce 478 a subset of possible SDDs.

479 Mapping of size distributions from LiDAR data will only work if additional layers of

480 information are provided to the algorithm to help refine its predictions. A single SDD in different 481 locations will not always produce the same HDLIDAR as a result of allometric noise; although we 482 are not proposing to invert the model, but to use it directly to predict an array of SDD-to483 HDPREDICT pairings, noise is still likely to pose an issue (Comerón et al. 2004, Clewley et al. 484 2012). While our model alone is therefore not adequate to predict the precise structure and 485 composition of a given stand, it does provide efficient and reliable predictions within a Bayesian 486 framework that incorporates other sources of information. For example, our study area had 487 previously been classified into forest types using imagery (Franklin et al. 2000) and including 488 this information as a prior in the Bayesian analysis can substantially improve its predictive 489 accuracy. Previous studies have also used statistical relationships drawn from LiDAR metrics to 490 achieve predictions of plot level statistics which can also be used to better constrain our model 491 (e.g. Popescu, Wynne, and Nelson 2003; Asner et al. 2010). In this way, we propose drawing on 492 multiple different sources of information within a flexible framework to make the most confident 493 predictions when applying our model to estimate SDDs.

495 alternative approach to the one we have adopted, and has the advantage of providing information 496 on the location of trees within each plot (Koch et al. 2006). However, this approach has its 
497 limitations: it is hard to detect understory trees (Maltamo et al. 2004) and segmentation is often

498 difficult in dense, deciduous stands (Koch et al. 2006), although predictions can be improved by

499 fusing LiDAR with multispectral data (Popescu et al. 2003). Incorporating spatial information

500 into the model would also improve the predictions made by the gap-fraction feature, (Gaulton

501 and Malthus 2010), although the extra complexity might compromise the applicability of the

502 model to large scale mapping.

504 Generalising the approach to other forest types

505 A significant benefit of developing a model from first principles is that it can be tuned for 506 applications in different forest types. None of the features included in the model are specific to

507 the study area, so the model can be re-calibrated for a new study area in which a set of

508 inventoried plots and the associated LiDAR first return distributions are available. The only

509 requirements to use the model are reliable measurements, or an existing allometry, predicting the

510 height and crown size, but not crown taper, for the predominant species; our work suggests that

511 using published allometries from one or two common species will be sufficient for this as

512 including ten allometries did not substantially improve model performance. All of the parameters

513 in our model can be estimated using the non-spatial ground data and low density LiDAR

514 distributions.

515 We used first returns only in our model to minimise the effects of instrument type (Næsset

516 2004), recognising that power, pulse frequency, footprint and scan angle all affect signal (Disney

517 et al. 2010). The generality of LiDAR derived methods for estimating canopy attributes can be

518 affected by differences in LiDAR acquisition specifications (Hopkinson 2007). First returns are

519 most clearly associated with the outer canopy shell, and thus can be related directly to crown 
520 allometries. Subsequent returns are reliant on interior canopy properties, such as foliage

521 clumping (Ni-Meister et al. 2001), and are consequently much more complicated to model

522 (North et al. 2010). Under different specifications, the internal structure of the canopy will be

523 captured very differently, and therefore would be hard to represent with a generic model. By

524 working only with the first returns and summarising these returns into a height distribution, we

525 reduce the problems associated with different LiDAR devices and increase the applicability of 526 our model to other temperate or coniferous forest types.

527 LiDAR offers wall-to-wall data for describing heterogeneous forest landscapes that are

528 difficult to sample with ground plots (Asner et al. 2010, Mitchard et al. 2014). Our study

529 represents an important step in the development of approaches for mapping SDDs.

\section{Acknowledgements}

532 We would like to thank the following people for their fieldwork efforts: Elaine Mallory, Jason

533 Kerr, Michelle Bowman, Gareth Cockwell, Cheryl Widdifield, Assunta Saliola, Alecia

534 Korkowski, Adam Gorgolewski, Mike Gillespie and Matt Thiel. We thank Drew Purves for his

535 helpful comments on an earlier version of this manuscript. We thank the anonymous reviewers

536 for their valuable contributions to improving the manuscript. RAS was funded by a Microsoft

537 Research scholarship. NSERC, Ontario Power Generation and Haliburton Forest funded other 538 aspects of this work.

\section{References}


541 Asner, G. P., J. Mascaro, H. C. Muller-Landau, G. Vieilledent, R. Vaudry, M. Rasamoelina, J. S.

542 Hall, and M. van Breugel. 2012. A universal airborne LiDAR approach for tropical forest $543 \quad$ carbon mapping. Oecologia 168:1147-1160.

544 Asner, G. P., G. V. N. Powell, J. Mascaro, D. E. Knapp, J. K. Clark, J. Jacobson, T. Kennedy545 Bowdoin, A. Balaji, G. Paez-Acosta, E. Victoria, L. Secada, M. Valqui, and R. F. Hughes. 546 2010. High-resolution forest carbon stocks and emissions in the Amazon. Proceedings of 547 the National Academy of Sciences of the United States of America 107:16738-42.

548 Breidenbach, J., C. Gläser, and M. Schmidt. 2008. Estimation of diameter distributions by means 549 of airborne laser scanner data. Canadian Journal of Forest Research 38:1611-1620.

550 Bugmann, H. 2001. A review of forest gap models. Climatic Change 51:259-305.

551 Canadian climate normals 1971-2000: Haliburton, Ontario. 2012. National Climate Data and 552 Information Archive.

553 Canham, C. D., P. T. Lepage, and K. D. Coates. 2004. A neighborhood analysis of canopy tree $554 \quad$ competition : effects of shading versus crowding 787:778-787.

555 Caspersen, J. P., M. C. Vanderwel, W. G. Cole, and D. W. Purves. 2011. How stand productivity 556 results from size- and competition-dependent growth and mortality. PLoS ONE 6.

557 Chasmer, L., C. Hopkinson, and P. Treitz. 2006. Investigating laser pulse penetration through a 558 conifer canopy by integrating airborne and terrestrial lidar. Canadian Journal of Remote $559 \quad$ Sensing 32:116-125. 
560 Clewley, D., R. Lucas, M. Moghaddam, and P. Bunting. 2012. The effects of noise on model 561 inversion for the retrieval of forest structure from SAR data. Pages 7173-7176 IEEE 562 International Geoscience and Remote Sensing Symposium (IGARSS). IEEE Press, New $563 \quad$ York.

564 Comerón, A., F. Rocadenbosch, M. A. López, A. Rodríguez, C. Muñoz, D. García-Vizcaíno, and 565 M. Sicard. 2004. Effects of noise on lidar data inversion with the backward algorithm. $566 \quad$ Applied Optics 43:2572-2577.

567 Coomes, D. A., and R. B. Allen. 2007. Mortality and tree-size distributions in natural mixed-age 568 forests $95: 27-40$.

569 Coomes, D. A., E. R. Lines, and R. B. Allen. 2011. Moving on from Metabolic Scaling Theory: 570 hierarchical models of tree growth and asymmetric competition for light. Journal of $571 \quad$ Ecology 99:748-756.

572 Dalponte, M., L. Bruzzone, and D. Gianelle. 2011. A system for the estimation of single-tree 573 stem diameter and volume using multireturn LiDAR data. IEEE Transactions on $574 \quad$ Geoscience and Remote Sensing 49:2479-2490.

575 Disney, M. I., V. Kalogirou, P. Lewis, a. Prieto-Blanco, S. Hancock, and M. Pfeifer. 2010.

576 Simulating the impact of discrete-return lidar system and survey characteristics over young $577 \quad$ conifer and broadleaf forests. Remote Sensing of Environment 114:1546-1560. 
578 Franklin, S. E., R. J. Hall, L. M. Moskal, a. J. Maudie, and M. B. Lavigne. 2000. Incorporating

579 texture into classification of forest species composition from airborne multispectral images.

$580 \quad$ International Journal of Remote Sensing 21:61-79.

581 Garber, S. M., and D. A. Maguire. 2005. The response of vertical foliage distribution to spacing

582 and species composition in mixed conifer stands in central Oregon. Forest Ecology and

$583 \quad$ Management 211:341-355.

584 Gaulton, R., and T. J. Malthus. 2010. LiDAR mapping of canopy gaps in continuous cover

585 forests: A comparison of canopy height model and point cloud based techniques.

586 International Journal of Remote Sensing 31:1193-1211.

587 Gaveau, D. L. A., and R. A. Hill. 2003. Quantifying canopy height underestimation by laser 588 pulse penetration in small-footprint airborne laser scanning data. Canadian Journal of $589 \quad$ Remote Sensing 29:650-657.

590 Goodwin, N. R., N. C. Coops, and D. S. Culvenor. 2007. Development of a simulation model to 591 predict LiDAR interception in forested environments. Remote Sensing of Environment $592 \quad 111: 481-492$.

593 Hill, A., J. Breschan, and D. Mandallaz. 2014. Accuracy Assessment of Timber Volume Maps 594 Using Forest Inventory Data and LiDAR Canopy Height Models. Forests:2253-2275.

595 Hopkinson, C. 2007. The influence of flying altitude, beam divergence, and pulse repetition 596 frequency on laser pulse return intensity and canopy frequency distribution. Canadian $597 \quad$ Journal of Remote Sensing 33:312-324. 
598 Hyyppä, J., O. Kelle, M. Lehikoinen, and M. Inkinen. 2001. A segmentation-based method to 599 retrieve stem volume estimates from 3-D tree height models produced by laser scanners. 600 IEEE Transactions on Geoscience and Remote Sensing 39:969-975.

601 Jakubowski, M. K., Q. Guo, and M. Kelly. 2013. Tradeoffs between lidar pulse density and 602 forest measurement accuracy. Remote Sensing of Environment 130:245-253.

603 Jochem, A., M. Hollaus, M. Rutzinger, and B. Höfle. 2010. Estimation of Aboveground Biomass 604 in Alpine Forests: A Semi-Empirical Approach Considering Canopy Transparency Derived 605 from Airborne LiDAR Data. Sensors 11:278-295.

606 Jones, T., M. Woods, and K. Lim. 2009. Quantifying diameter and basal area distributions of 607 uneven-aged tolerant hardwood stands using low density LiDAR. Silvilaser 2009, Oct 14$608 \quad 16$.

609 Kirschbaum, M. U. F. 1999. CenW, a forest growth model with linked carbon, energy, nutrient 610 and water cycles. Ecological Modelling 118:17-59.

611 Koch, B., U. Heyder, and H. Weinacker. 2006. Detection of Individual Tree Crowns in Airborne $612 \quad$ Lidar Data 72:357-363.

613 Köhler, P., and A. Huth. 1998. The effects of tree species grouping in tropical rain forest 614 modelling Simulations with the individual based model Formind. Ecological Modelling $615 \quad 109: 301-321$. 
616 Koukoulas, S., and G. A. Blackburn. 2004. Quantifying the spatial properties of forest canopy

617 gaps using LiDAR imagery and GIS. International Journal of Remote Sensing 25:3049-

$618 \quad 3072$.

619 Van Leeuwen, M., N. C. Coops, T. Hilker, M. a. Wulder, G. J. Newnham, and D. S. Culvenor.

620 2013. Automated reconstruction of tree and canopy structure for modeling the internal

621 canopy radiation regime. Remote Sensing of Environment 136:286-300.

622 Van Leeuwen, M., N. C. Coops, and M. a. Wulder. 2010. Canopy surface reconstruction from a

623 LiDAR point cloud using Hough transform. Remote Sensing Letters 1:125-132.

624 Van Leeuwen, M., and M. Nieuwenhuis. 2010. Retrieval of forest structural parameters using

625 LiDAR remote sensing. European Journal of Forest Research 129:749-770.

626 Li, W., Q. Guo, M. K. Jakubowski, and M. Kelly. 2012. A New Method for Segmenting

627 Individual Trees from the Lidar Point Cloud 78:75-84.

628 Lim, K., P. Treitz, M. Wulder, B. St-Onge, and M. Flood. 2003. LiDAR remote sensing of forest 629 structure. Progress in Physical Geography 27:88-106.

630 Lines, E. R., D. A. Coomes, and D. W. Purves. 2010. Influences of forest structure, climate and 631 species composition on tree mortality across the eastern US. PloS one 5:e13212.

632 Maltamo, M., K. Eerikäinen, P. Packalén, and J. Hyyppä. 2006. Estimation of stem volume using 633 laser scanning-based canopy height metrics. Forestry 79:217-229. 
Maltamo, M., K. Mustonen, J. Hyyppä, J. Pitkänen, and X. Yu. 2004. The accuracy of estimating individual tree variables with airborne laser scanning in a boreal nature reserve. Canadian Journal of Forest Research 34:1791-1801.

Mitchard, E. T. A., T. R. Feldpausch, R. J. W. Brienen, G. Lopez-Gonzalez, A. Monteagudo, T. R. Baker, S. L. Lewis, J. Lloyd, C. A. Quesada, M. Gloor, H. ter Steege, P. Meir, E. Alvarez, A. Araujo-Murakami, L. E. O. C. Aragão, L. Arroyo, G. Aymard, O. Banki, D. Bonal, S. Brown, F. I. Brown, C. E. Cerón, V. Chama Moscoso, J. Chave, J. a. Comiskey, F. Cornejo, M. Corrales Medina, L. Da Costa, F. R. C. Costa, A. Di Fiore, T. F. Domingues, T. L. Erwin, T. Frederickson, N. Higuchi, E. N. Honorio Coronado, T. J. Killeen, W. F. Laurance, C. Levis, W. E. Magnusson, B. S. Marimon, B. H. Marimon Junior, I. Mendoza Polo, P. Mishra, M. T. Nascimento, D. Neill, M. P. Núñez Vargas, W. A. Palacios, A. Parada, G. Pardo Molina, M. Peña-Claros, N. Pitman, C. A. Peres, L. Poorter, A. Prieto, H. Ramirez-Angulo, Z. Restrepo Correa, A. Roopsind, K. H. Roucoux, A. Rudas, R. P. Salomão, J. Schietti, M. Silveira, P. F. de Souza, M. K. Steininger, J. Stropp, J. Terborgh, R. Thomas, M. Toledo, A. Torres-Lezama, T. R. van Andel, G. M. F. van der Heijden, I. C. G. Vieira, S. Vieira, E. Vilanova-Torre, V. A. Vos, O. Wang, C. E. Zartman, Y. Malhi, and O. L. Phillips. 2014. Markedly divergent estimates of Amazon forest carbon density from ground plots and satellites. Global Ecology and Biogeography 23:935-946.

Næsset, E. 2002. Predicting forest stand characteristics with airborne scanning laser using a practical two-stage procedure and field data. Remote Sensing of Environment 80:88 - 99. 
654 Næsset, E. 2004. Effects of different flying altitudes on biophysical stand properties estimated 655 from canopy height and density measured with a small-footprint airborne scanning laser. 656 Remote Sensing of Environment 91:243-255.

657 Nelson, R. 1997. Modeling forest canopy heights: The effects of canopy shape. Remote Sensing 658 of Environment 60:327-334.

659 Ni-Meister, W., D. L. B. Jupp, and R. Dubayah. 2001. Modeling Lidar Waveforms in 660 Heterogeneous and Discrete Canopies. IEEE Transactions on Geoscience and Remote $661 \quad$ Sensing 39:1943-1958.

662 Nock, C. a, J. P. Caspersen, and S. C. Thomas. 2008. Large ontogenetic declines in intra-crown 663 leaf area index in two temperate deciduous tree species. Ecology 89:744-53.

664 North, P., J. Rosette, J. Suárez, and S. Los. 2010. A Monte Carlo radiative transfer model of 665 satellite waveform LiDAR. International Journal of Remote Sensing 31:1343-1358.

666 Parker, G. R., D. J. Leopold, and J. K. Eichenberger. 1985. Tree dynamics in an old-growth, 667 deciduous forest. Forest Ecology and Management 11:31-57.

668 Piboule, A., C. Collet, H. Frochot, and J. Dhôte. 2005. Reconstructing crown shape from stem 669 diameter and tree position to supply light models . I. Algorithms and comparison of light $670 \quad$ simulations. Annals of Forest Science 62:645-657.

671 Popescu, S. C., R. H. Wynne, and R. F. Nelson. 2003. Measuring individual tree crown diameter 672 with lidar and assessing its influence on estimating forest volume and biomass. Canadian $673 \quad$ Journal of Remote Sensing 29:564-577. 
674 Purves, D., and V. Lyutsarev. 2011. Filzbach user guide version 1.1.

675 Purves, D. W., J. W. Lichstein, and S. W. Pacala. 2007. Crown plasticity and competition for 676 canopy space: a new spatially implicit model parameterized for 250 North American tree $677 \quad$ species. PloS one 2:e870.

678 Purves, D. W., J. W. Lichstein, N. Strigul, and S. W. Pacala. 2008. Predicting and understanding 679 forest dynamics using a simple tractable model. Proceedings of the National Academy of 680 Sciences of the United States of America 105:17018-22.

681 Scheller, R. M., and D. J. Mladenoff. 2004. A forest growth and biomass module for a landscape 682 simulation model, LANDIS: design, validation, and application. Ecological Modelling $683 \quad 180: 211-229$.

684 Sullivan, T. P., D. S. Sullivan, and P. M. F. Lindgren. 2001. Stand Structure and Small Mammals 685 in Young Lodgepole Pine Forest : 10-Year Results after Thinning 11:1151-1173.

686 Sun, G., and K. J. Ranson. 2000. Modeling Lidar Returns from Forest Canopies. IEEE 687 Transactions on Geoscience and Remote Sensing 38:2617-2626.

688 Thomas, V., R. D. Oliver, K. Lim, and M. Woods. 2008. LiDAR and Weibull modeling of 689 diameter and basal area. Forestry 84:866-875.

690 Valbuena, R., P. Packalen, L. Mehtätalo, A. García-Abril, and M. Maltamo. 2013. Characterizing 691 forest structural types and shelterwood dynamics from Lorenz-based indicators predicted by 692 airborne laser scanning. Canadian Journal of Forest Research 43:1063-1074. 
693 Vanderwel, M. C., H. C. Thorpe, J. L. Shuter, J. P. Caspersen, and S. C. Thomas. 2008.

694 Contrasting downed woody debris dynamics in managed and unmanaged northern

695 hardwood stands. Canadian Journal of Forest Research 38:2850-2861.

696 Vauhkonen, J., and L. Mehtätalo. 2015. Matching remotely sensed and field-measured tree size

697 distributions. Canadian Journal of Forest Research 45:353-363.

698 Vincent, G., D. Sabatier, L. Blanc, J. Chave, E. Weissenbacher, R. Pélissier, E. Fonty, J. F.

699 Molino, and P. Couteron. 2012. Accuracy of small footprint airborne LiDAR in its

700 predictions of tropical moist forest stand structure. Remote Sensing of Environment

$701 \quad 125: 23-33$.

702 Xu, Q., Z. Hou, M. Maltamo, and T. Tokola. 2014. Calibration of area based diameter

703 distribution with individual tree based diameter estimates using airborne laser scanning.

704 ISPRS Journal of Photogrammetry and Remote Sensing 93:65-75.

705 Yao, W., P. Krzystek, and M. Heurich. 2012. Tree species classification and estimation of stem

706 volume and DBH based on single tree extraction by exploiting airborne full-waveform

707 LiDAR data. Remote Sensing of Environment 123:368-380.

708 Zhao, K., S. Popescu, and R. Nelson. 2009. Lidar remote sensing of forest biomass: A scale-

709 invariant estimation approach using airborne lasers. Remote Sensing of Environment

$710 \quad 113: 182-196$.

711

712 
Table 1 A performance summary of the different versions of the model. The deviance information criterion (DIC) estimated from the model-fitting plots and summary statistics for the RMSE measured for each test plot is presented for each model (the percentage RMSE is the mean RMSE as a proportion of the range of true values; see equations (S. 2) and (S. 3)). A decrease in both DIC and RMSE corresponds to an improvement in the model.

\begin{tabular}{|c|c|c|c|c|}
\hline Model version & $\begin{array}{l}\text { No. crown } \\
\text { allometries }\end{array}$ & $\begin{array}{l}\text { No. } \\
\text { parameters } \\
\text { fitted using } \\
\text { LiDAR* }\end{array}$ & DIC & $\begin{array}{c}\text { Mean RMSE } \pm \text { standard } \\
\text { deviation } \\
(\% \text { RMSE })\end{array}$ \\
\hline \multirow{3}{*}{ Basic allometric } & 1 & 0 & & $0.0433 \pm 0.0091(39.7 \%)$ \\
\hline & 2 & 0 & & $0.0388 \pm 0.0085(35.3 \%)$ \\
\hline & 10 & 0 & & $0.0351 \pm 0.0092(32.1 \%)$ \\
\hline \multirow{3}{*}{ Gap fraction } & 1 & 1 & -13744 & $0.0417 \pm 0.0090(38.3 \%)$ \\
\hline & 2 & 1 & -14884 & $0.0372 \pm 0.0086(34.0 \%)$ \\
\hline & 10 & 1 & -15596 & $0.0335 \pm 0.0093(30.7 \%)$ \\
\hline \multirow{3}{*}{ Crown taper } & 1 & 1 & -18253 & $0.0231 \pm 0.0094(20.2 \%)$ \\
\hline & 2 & 2 & -18684 & $0.0221 \pm 0.0077(19.5 \%)$ \\
\hline & 10 & 10 & -18954 & $0.0217 \pm 0.0078(19.1 \%)$ \\
\hline \multirow{3}{*}{$\begin{array}{c}\text { Crown } \\
\text { permeability }\end{array}$} & 1 & 1 & -14345 & $0.0374 \pm 0.0010(34.4 \%)$ \\
\hline & 2 & 1 & -15611 & $0.0331 \pm 0.0085(30.2 \%)$ \\
\hline & 10 & 1 & -16388 & $0.0296 \pm 0.0094(27.2 \%)$ \\
\hline \multirow{3}{*}{ Crown overlap } & 1 & 1 & -13374 & $0.0433 \pm 0.0091(39.7 \%)$ \\
\hline & 2 & 1 & -14483 & $0.0388 \pm 0.0085(35.3 \%)$ \\
\hline & 10 & 1 & -15121 & $0.0351 \pm 0.0092(32.1 \%)$ \\
\hline \multirow{3}{*}{ Full } & 1 & 4 & -19057 & $0.0208 \pm 0.0091(18.2 \%)$ \\
\hline & 2 & 5 & -19634 & $0.0196 \pm 0.0075(17.3 \%)$ \\
\hline & 10 & 13 & -19962 & $0.0196 \pm 0.0074(17.5 \%)$ \\
\hline
\end{tabular}

$713 *$ The number of fitted parameters is one greater than the numbers provided here when the error 714 term used to calculate the likelihood is included. 


\section{$716 \quad$ Figure captions}

717 Fig. 1 The extent of the LiDAR data across Haliburton Forest (grey boxed area; each complete

718 box is $1 \mathrm{~km}^{2}$ ) and the locations of all of the inventoried plots (black dots; note that the dots are 719 not to scale).

721 Fig. 2 (a) Species-specific crown properties predicted from stem diameter at breast height (dbh)

722 using allometric functions (Table S.1): these include tree height $(\mathrm{H})$, crown depth $(\mathrm{V})$, maximum

723 crown radius $\left(R_{\max }\right)$ as well as the crown radius $\left(\mathrm{R}_{\mathrm{h}}\right)$ and crown area $\left(\mathrm{CA}_{h}\right)$ at a given

724 measurement height (h); (b) $E C A_{[h, h+1)}$ (exposed canopy area between height $\mathrm{h}$ and $\mathrm{h}+1$ ) is

725 calculated by subtracting the crown area at $h+1$ from the crown area at height $h$.

726

727 Fig. 3 The link model developed in this study can take SDDs classified as conifers or

728 broadleaves and predicts the height distribution of LiDAR first returns (HDPREDICT) from a few

729 simple assumptions about canopy structure. We propose that this model can then be used in the

730 inverse prediction to obtain predicted stand information from an observed LiDAR distribution

731 (HD LIDAR).

732

733 Fig. 4 Histogram of the LiDAR first return distribution summarised across all of the test plots.

734 The line overlaying the histogram represents the prediction made by the full model in each of the

735 three allometric versions. The inset presents the deviance from the 1:1 line of the predictions

736 made by the species-specific full model with the associated RMSE. 
738 Fig. 5 Individual LiDAR return distributions for twelve test plots where the histograms represent

739 the data and the lines show the prediction made by the full species-specific model. The top row

740 are from the top $25 \%$ best fitting plots (RMSE $<0.0148$ ), the middle row are from the middle

$74150 \%(0.0148 \leq \mathrm{RMSE}<0.0253)$ and the bottom row are from the worst $25 \%(\mathrm{RMSE} \geq 0.0253)$.

742 The RMSE values for each plot are displayed in the top right corner.

744 Fig. 6 The main figure presents the RMSE of all test plots to compare the performances of the

745 basic model and full model (containing all features) for each of the model versions using: a

746 single crown allometry (1), a generic allometry each for broadleaf and conifer (2) and the

747 species-specific crown allometries (10). A RMSE value of 0 would correspond to a perfect fit.

748 The inset figure shows the effect of incorporating the features into the basic model individually

749 in each version of the model. The dotted horizontal lines denote the median RMSE for the single

750 allometry basic model (upper) and the ten allometry full model (lower) for comparison; gap

751 fraction, crown taper and crown permeability are all shown to correspond with a significant

752 improvement in model performance, whilst crown overlap does not improve on the basic model

753 when considered individually.

755 Fig. 7 Gap fraction in a) is predicted as the proportion of first returns being recorded from the

756 ground as a function of the total canopy area as a proportion of the plot area. The points are the

757 actual recorded ground returns. The permeability factor is interpreted in b) where the solid

758 circles outline the ECA in an example $1 \mathrm{~m}$ height interval with the grey shaded area denoting the

759 area where first returns are recorded in that interval. The lighter shaded area gives the region

760 where the first returns have permeated from the interval above (fitted proportion of 0.65) and the 
761 hashed area gives the region where the first returns will permeate to the interval below. The

762 crown overlap correction factor in c) is predicted from the cumulative canopy area as a

763 proportion of the plot area.

764

765 Fig. 8 Comparison of allometry-derived crown forms (dotted line) and fitted crown forms using

766 the LiDAR data (solid line) for trees with a dbh of $30 \mathrm{~cm}$; the grey shaded area denotes the $95 \%$

767 confidence interval associated with the fitted crown shape parameter $(\beta)$.

768

769

770

771

772

773

774

775

776 


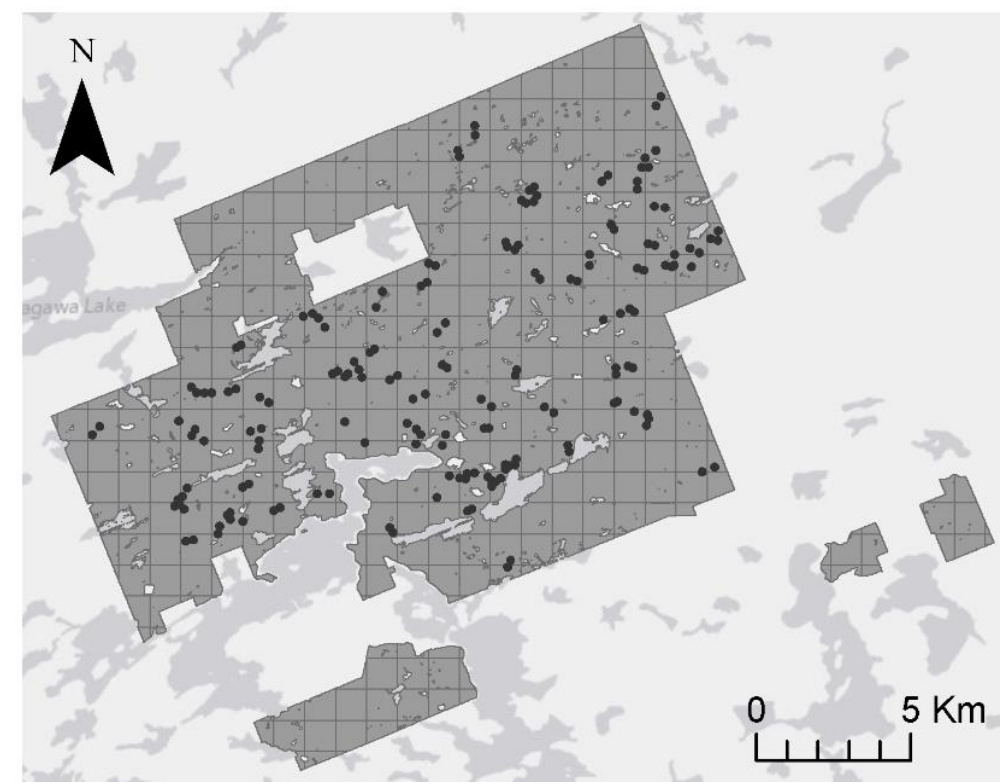

Fig. 1 The extent of the LiDAR data across Haliburton Forest (grey boxed area; each complete box is $1 \mathrm{~km}^{2}$ ) and the locations of all of the inventoried plots (black dots; note that the dots are not to scale). 
a)

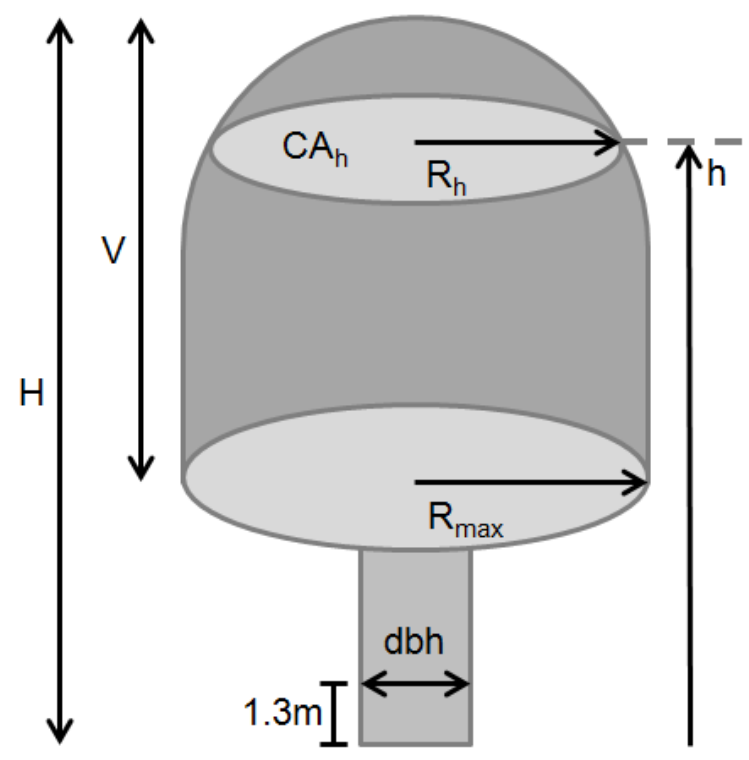

b)

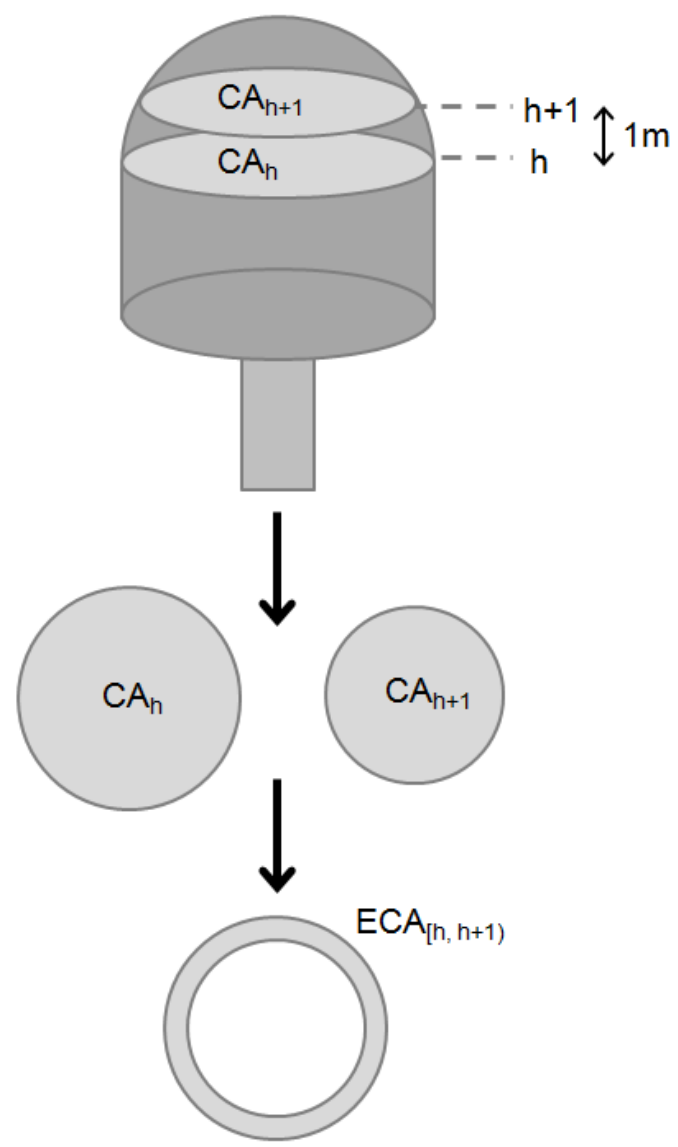

Fig. 2 (a) Species-specific crown properties predicted from stem diameter at breast height (dbh) using allometric functions (Table S.1): these include tree height $(\mathrm{H})$, crown depth $(\mathrm{V})$, maximum crown radius $\left(\mathrm{R}_{\max }\right)$ as well as the crown radius $\left(\mathrm{R}_{\mathrm{h}}\right)$ and crown area $\left(\mathrm{CA}_{\mathrm{h}}\right)$ at a given measurement height (h); (b) $E C A_{[h, h+1)}$ (exposed canopy area between height $h$ and $h+1)$ is calculated by subtracting the crown area at $h+1$ from the crown area at height $h$. 


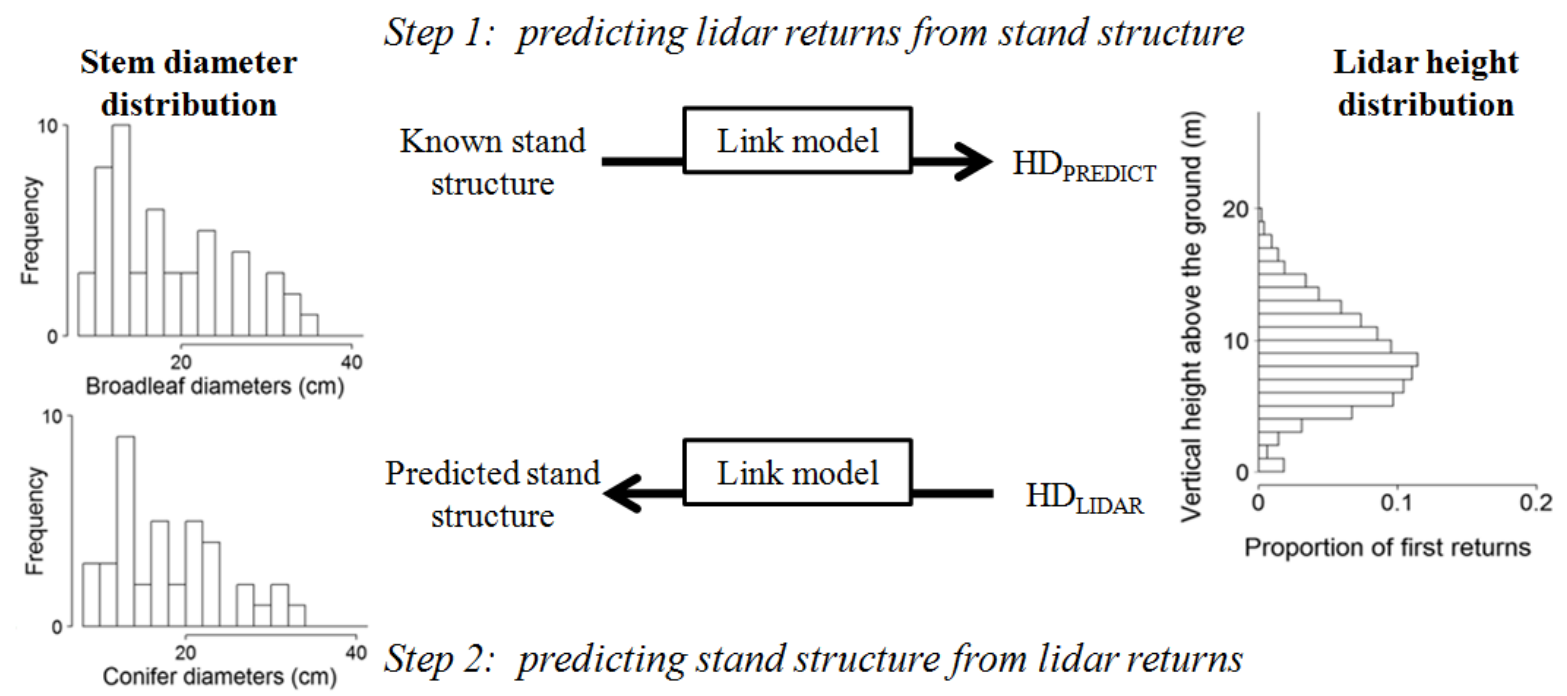

Fig. 3 The link model developed in this study can take SDDs classified as conifers or broadleaves and predicts the height distribution of LiDAR first returns (HDPREDICT) from a few simple assumptions about canopy structure. We propose that this model can then be used in the inverse prediction to obtain predicted stand information from an observed LiDAR distribution (HDLIDAR). 


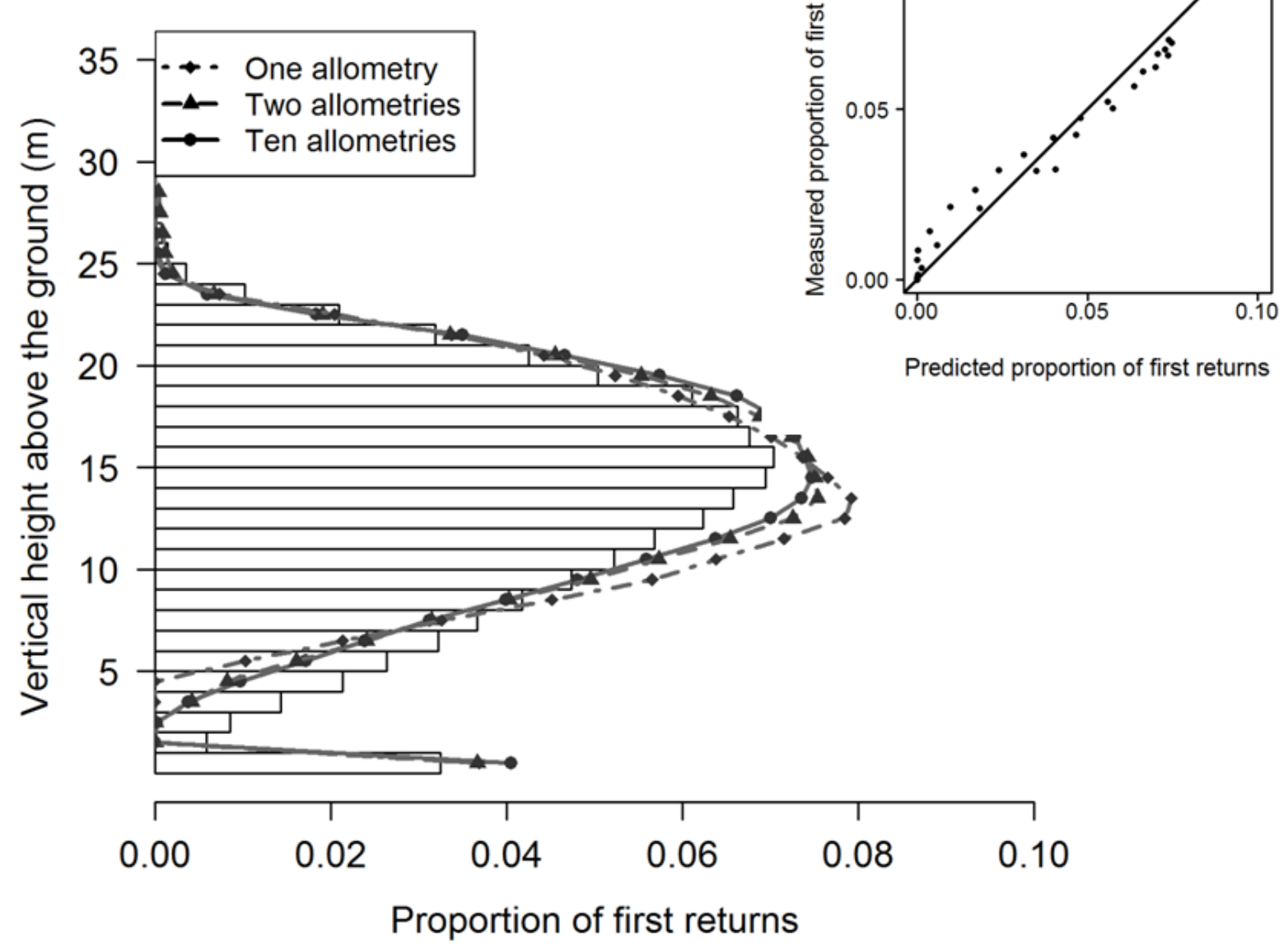

Fig. 4 Histogram of the LiDAR first return distribution summarised across all of the test plots. The line overlaying the histogram represents the prediction made by the full model in each of the three allometric versions. The inset presents the deviance from the $1: 1$ line of the predictions made by the species-specific full model with the associated RMSE. 
Four of the top $25 \%$ :
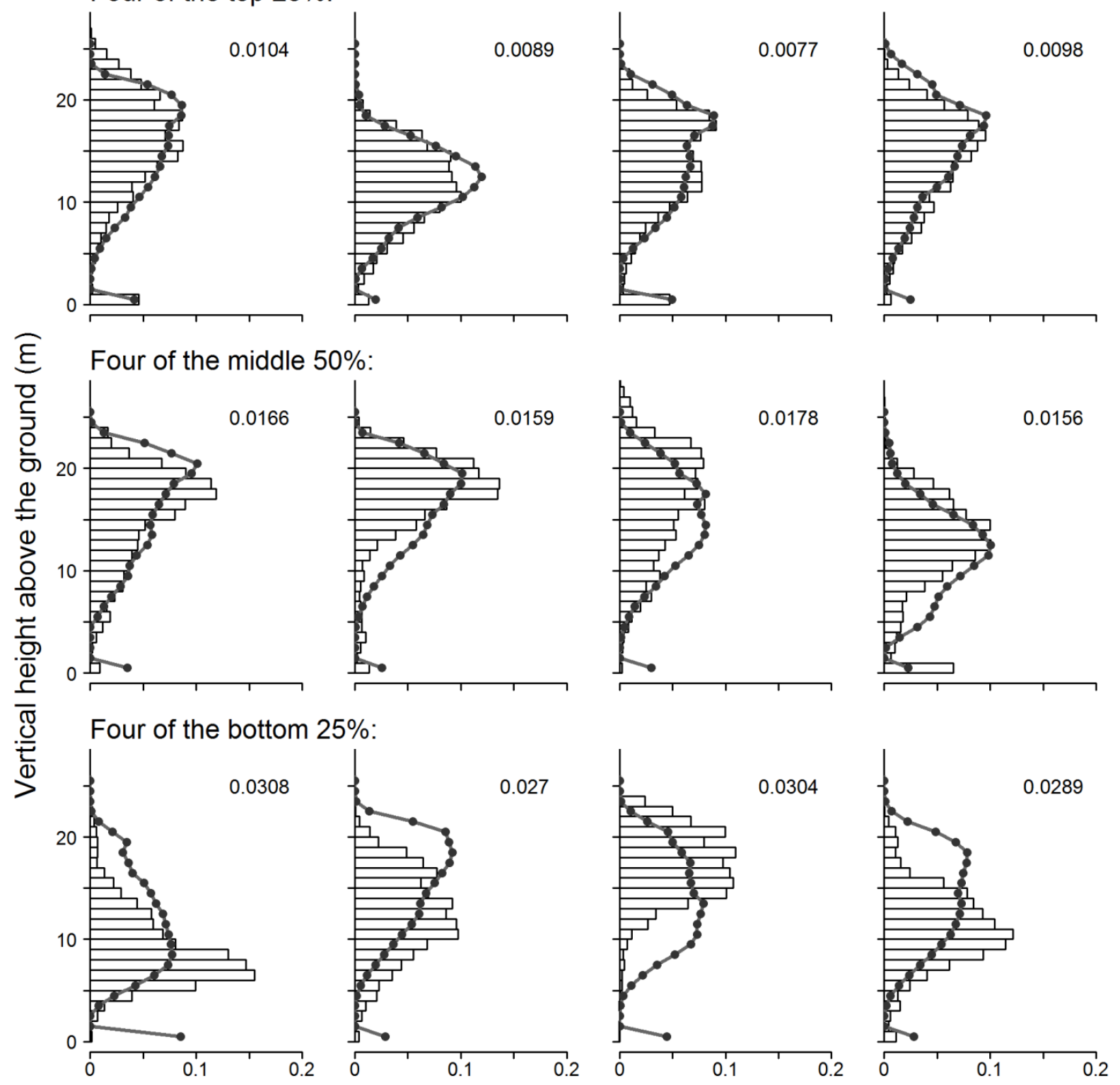

\section{Proportion of first returns}

Fig. 5 Individual LiDAR return distributions for twelve test plots where the histograms represent the data and the lines show the prediction made by the full species-specific model. The top row are from the top $25 \%$ best fitting plots $(\mathrm{RMSE}<0.0148)$, the middle row are from the middle $50 \%(0.0148 \leq \mathrm{RMSE}<0.0253)$ and the bottom row are from the worst $25 \%(\mathrm{RMSE} \geq 0.0253)$. The RMSE values for each plot are displayed in the top right corner. 

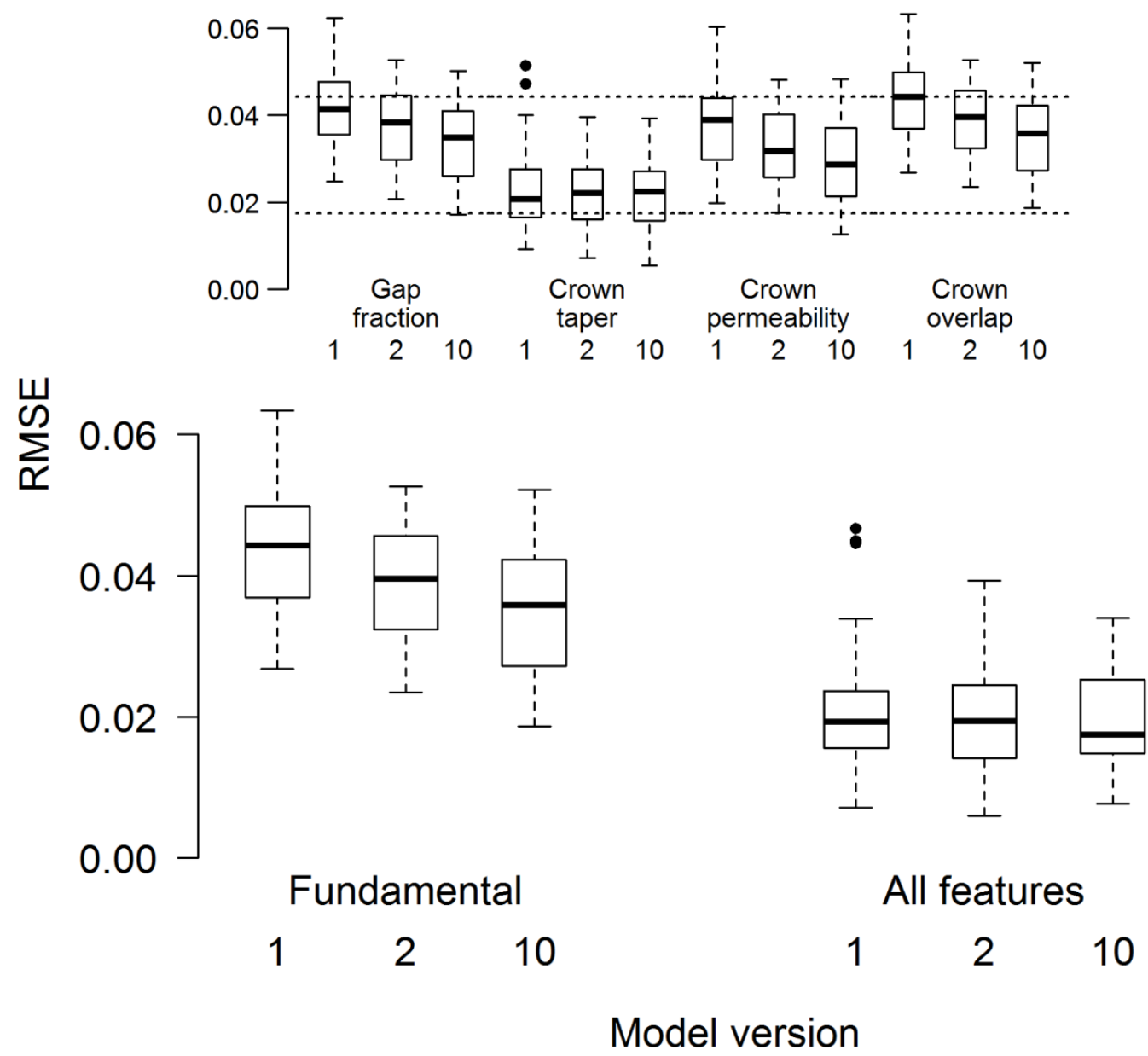

Fig. 6 The main figure presents the RMSE of all test plots to compare the performances of the basic model and full model (containing all features) for each of the model versions using: a single crown allometry (1), a generic allometry each for broadleaf and conifer (2) and the species-specific crown allometries (10). A RMSE value of 0 would correspond to a perfect fit. The inset figure shows the effect of incorporating the features into the basic model individually in each version of the model. The dotted horizontal lines denote the median RMSE for the single allometry basic model (upper) and the ten allometry full model (lower) for comparison; gap fraction, crown taper and crown permeability are all shown to correspond with a significant improvement in model performance, whilst crown overlap does not improve on the basic model when considered individually. 
a) Gap fraction

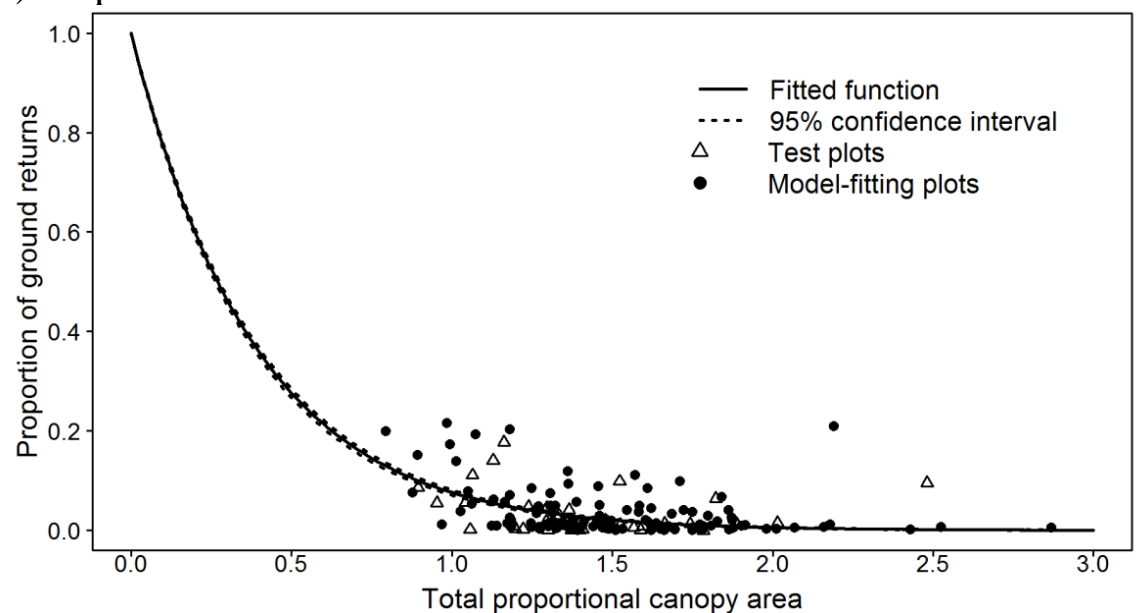

b) Crown permeability

c) Crown overlap
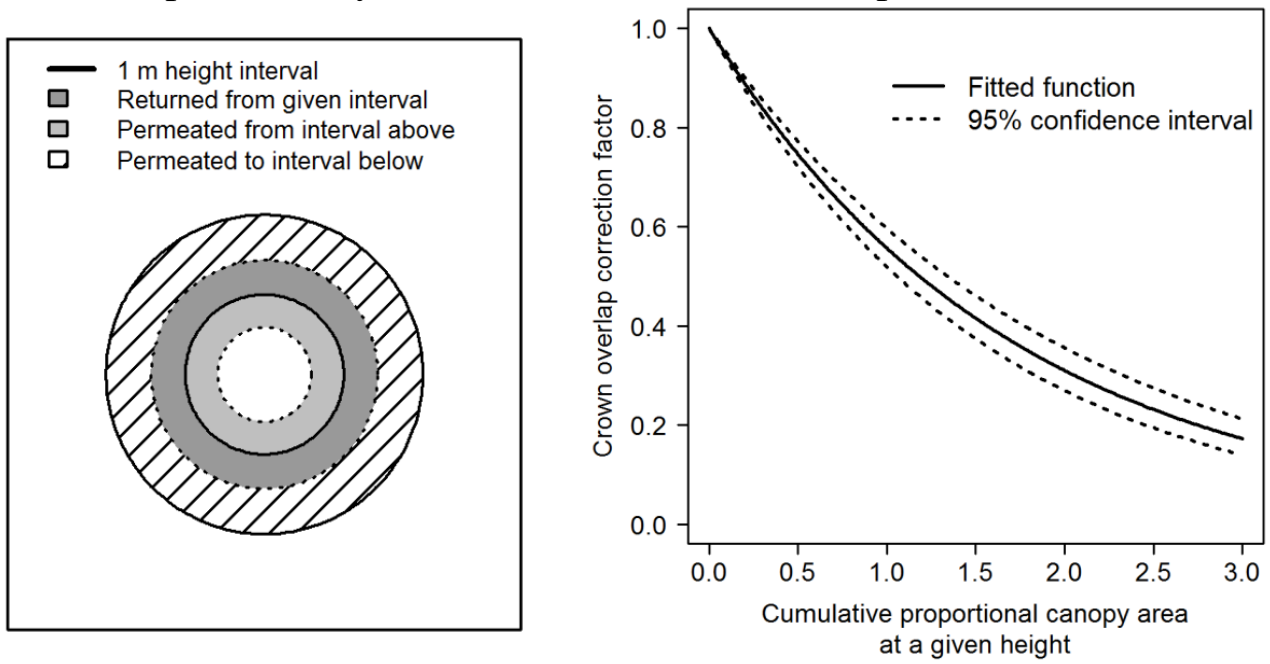

Fig. 7 Gap fraction in a) is the proportion of first returns being recorded from the ground as a function of the total canopy area divided by the plot area. The points are the recorded ground returns linked with the total canopy area predicted from the allometries. The permeability factor is interpreted in b) where the solid circles outline the ECA looking from above in an example 1 $m$ height interval with the grey shaded area denoting the area where first returns are recorded in that interval. The lighter shaded area gives the region where the first returns have permeated from the interval above (fitted proportion of 0.65) and the hashed area gives the region where the first returns permeate to the interval below. The crown overlap correction factor in c) is predicted from the cumulative canopy area as a proportion of the plot area. 


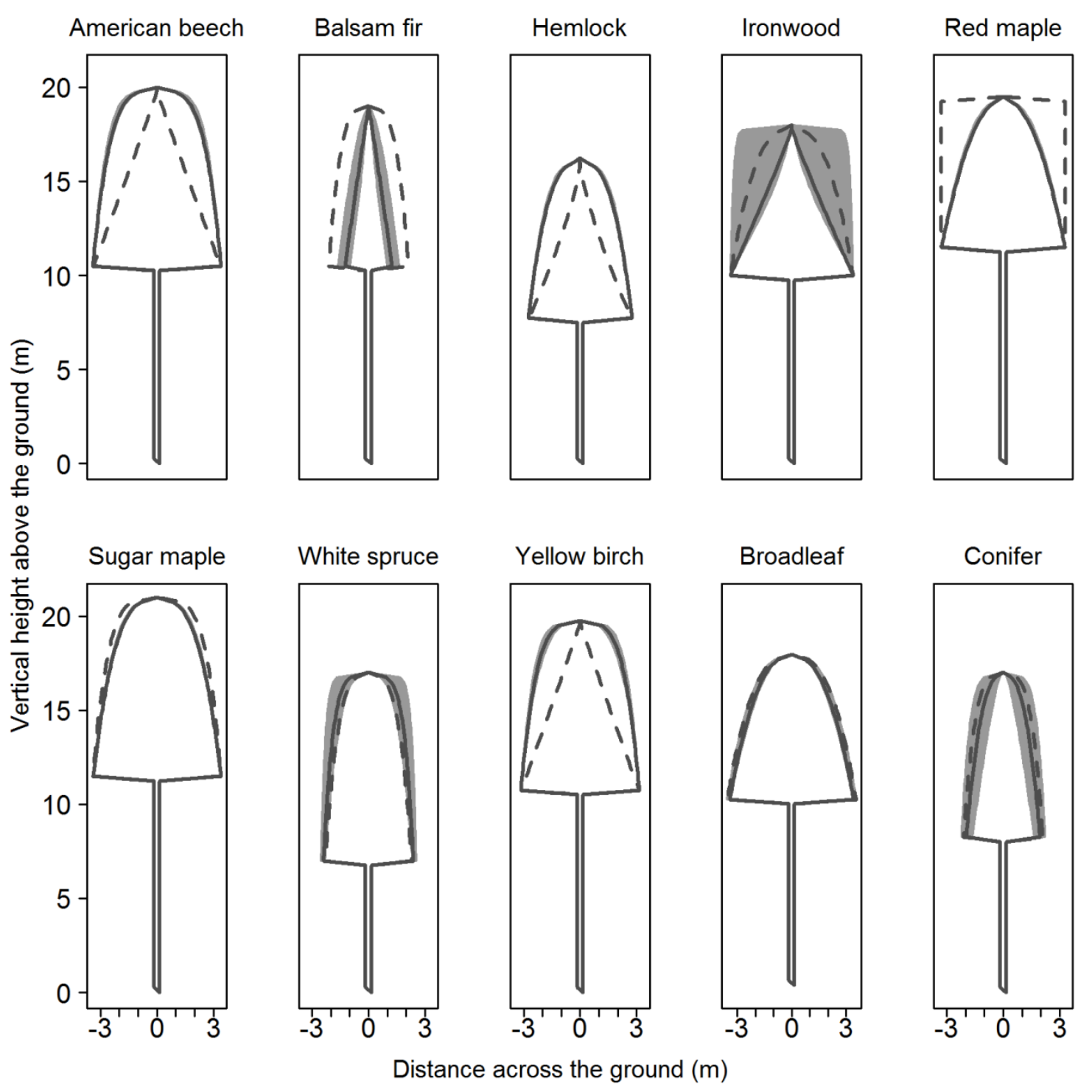

Fig. 8 Comparison of allometry-derived crown forms (dotted line) and fitted crown forms using the LiDAR data (solid line) for trees with a dbh of $30 \mathrm{~cm}$; the grey shaded area denotes the $95 \%$ confidence interval associated with the fitted crown shape parameter $(\beta)$. 


\section{Supplementary material}

$801 \quad$ Forest details

802 The details of the plots are given in Table S.1. The plots were selected to represent the full

803 variation present in the forest.

Table S.1 A summary of the forest plot properties where the plots are grouped by percentage ocular coverage. The stems are grouped into diameter classes with the stem diameters given in brackets: small poles $(\mathbf{8} \leq \boldsymbol{x} \leq \mathbf{1 7})$, large poles $(\mathbf{1 7}<\boldsymbol{x} \leq \mathbf{2 5})$, small logs $(\mathbf{2 5}<\boldsymbol{x} \leq \mathbf{3 7})$, medium logs $(37<x \leq 49)$ and large $\operatorname{logs}_{s}(49<x \leq \mathbf{1 0 0})$. The mean basal area $\left(\mathrm{BA} ; \mathrm{m}^{2} / \mathrm{ha}\right)$ and the corresponding standard deviation (s.d.) is given for each of these groups as well as the mean total BA and mean total stem density (no. stems/ha)

\begin{tabular}{|c|c|c|c|c|c|c|c|c|}
\hline $\begin{array}{c}\text { Ocular } \\
\text { coverage } \\
(\%)\end{array}$ & $\begin{array}{l}\text { No. } \\
\text { plots }\end{array}$ & $\begin{array}{c}\text { Mean } \\
\text { small } \\
\text { pole BA } \\
\text { (s.d.) }\end{array}$ & $\begin{array}{c}\text { Mean } \\
\text { large } \\
\text { pole BA } \\
\text { (s.d.) }\end{array}$ & $\begin{array}{c}\text { Mean } \\
\text { small log } \\
\text { BA } \\
\text { (s.d.) }\end{array}$ & $\begin{array}{c}\text { Mean } \\
\text { medium } \\
\log \text { BA } \\
\text { (s.d.) }\end{array}$ & $\begin{array}{c}\text { Mean } \\
\text { large log } \\
\text { BA } \\
\text { (s.d.) }\end{array}$ & $\begin{array}{c}\text { Mean } \\
\text { total BA } \\
\text { (s.d.) }\end{array}$ & $\begin{array}{c}\text { Mean } \\
\text { total } \\
\text { stem } \\
\text { density } \\
\text { (s.d.) }\end{array}$ \\
\hline $51-60$ & 32 & $\begin{array}{c}5.60 \\
(2.82)\end{array}$ & $\begin{array}{c}4.43 \\
(1.83)\end{array}$ & $\begin{array}{c}6.14 \\
(2.17)\end{array}$ & $\begin{array}{c}3.34 \\
(2.16)\end{array}$ & $\begin{array}{c}2.74 \\
(5.84)\end{array}$ & $\begin{array}{l}22.25 \\
(6.61)\end{array}$ & $\begin{array}{c}770 \\
(290)\end{array}$ \\
\hline $61-70$ & 22 & $\begin{array}{c}4.65 \\
(2.27)\end{array}$ & $\begin{array}{c}4.87 \\
(2.76)\end{array}$ & $\begin{array}{c}6.94 \\
(2.35)\end{array}$ & $\begin{array}{c}5.20 \\
(2.80)\end{array}$ & $\begin{array}{c}2.76 \\
(2.65)\end{array}$ & $\begin{array}{l}24.41 \\
(5.78)\end{array}$ & $\begin{array}{c}704 \\
(236)\end{array}$ \\
\hline $71-80$ & 44 & $\begin{array}{c}3.38 \\
(2.28)\end{array}$ & $\begin{array}{c}4.14 \\
(1.88)\end{array}$ & $\begin{array}{c}7.16 \\
(2.15)\end{array}$ & $\begin{array}{c}6.22 \\
(3.39)\end{array}$ & $\begin{array}{c}5.37 \\
(4.22)\end{array}$ & $\begin{array}{l}26.70 \\
(6.72)\end{array}$ & $\begin{array}{c}632 \\
(250)\end{array}$ \\
\hline $81-90$ & 41 & $\begin{array}{c}4.21 \\
(2.53)\end{array}$ & $\begin{array}{c}3.90 \\
(1.67)\end{array}$ & $\begin{array}{c}6.33 \\
(2.94)\end{array}$ & $\begin{array}{c}5.89 \\
(3.25)\end{array}$ & $\begin{array}{c}4.01 \\
(4.22)\end{array}$ & $\begin{array}{l}24.35 \\
(6.90)\end{array}$ & $\begin{array}{c}644 \\
(240)\end{array}$ \\
\hline $91-100$ & 15 & $\begin{array}{c}5.17 \\
(3.29)\end{array}$ & $\begin{array}{c}5.61 \\
(2.31)\end{array}$ & $\begin{array}{c}6.55 \\
(2.78)\end{array}$ & $\begin{array}{c}5.04 \\
(3.93)\end{array}$ & $\begin{array}{c}3.41 \\
(2.98)\end{array}$ & $\begin{array}{l}25.78 \\
(3.47)\end{array}$ & $\begin{array}{c}756 \\
(322)\end{array}$ \\
\hline
\end{tabular}

804 
806 The details of the LiDAR flight are provided in Table S.1.

Table S.1 The LiDAR flight details for Haliburton Forest, Ontario collected in August 2009.

\begin{tabular}{|c|c|c|}
\hline Settings & Definition & Flight plan specifications \\
\hline No. lines flown & $\begin{array}{l}\text { Number of passes that the aircraft } \\
\text { flew }\end{array}$ & 39 passes ( 3 control) \\
\hline Altitude & $\begin{array}{l}\text { Height at which the aircraft was } \\
\text { flown }\end{array}$ & $1500 \mathrm{~m}$ \\
\hline Overlap & $\begin{array}{l}\text { The degree to which the passes } \\
\text { overlap }\end{array}$ & $\begin{array}{l}30 \% \text { ( } 15 \% \text { on either side of } \\
\text { the pass) }\end{array}$ \\
\hline Speed & Speed at which the plane was flown & $120 \mathrm{kts}$ \\
\hline System PRF & Pulse repetition frequency & $70 \mathrm{kHz}$ \\
\hline Scan frequency & Number of pulses emitted per second & $36 \mathrm{~Hz}$ \\
\hline Scan half angle & $\begin{array}{l}\text { Angle at which the beam axis was } \\
\text { directed away from azimuth }\end{array}$ & $16^{\circ}$ \\
\hline Cross track resolution & $\begin{array}{l}\text { Space between pulses perpendicular } \\
\text { to the line of flight }\end{array}$ & $0.89 \mathrm{~m}$ \\
\hline Down track resolution & $\begin{array}{l}\text { Space between pulses along the line } \\
\text { of flight }\end{array}$ & $0.86 \mathrm{~m}$ \\
\hline Point density & $\begin{array}{l}\text { Number of first returns recorded per } \\
\mathrm{m}^{2}\end{array}$ & 2 points $\mathrm{m}^{-2}$ \\
\hline Footprint size & $\begin{array}{l}\text { Area covered by a single beam on } \\
\text { the ground }\end{array}$ & $0.14 \mathrm{~m}^{2}$ \\
\hline
\end{tabular}




\section{Published allometries}

812 The published allometries used to make predictions for the tree crowns, and thus the canopy

813 structure, are detailed in Table S.1.

Table S.1 The allometric equations used to derive canopy area at a given height from the measurements of diameter at breast height $(\mathrm{dbh})$ for an individual tree of species $\mathrm{j}$. The equation and coefficients detailed in (Caspersen et al. 2011) were used in preference to (Purves et al. 2007) where available.

\section{Scaling}

relationship

(a) Caspersen et al. (2011)

(b) Purves et al. (2007)

Height (H)

$$
\begin{aligned}
& H=1.3+\left(\eta_{j}-1.3\right) \cdot(1- \\
& \left.e^{\left(\frac{-\phi_{j} \cdot d b h}{\eta_{j}-1.3}\right)}\right)
\end{aligned}
$$$$
\log (H)=a_{j}+b_{j} \cdot \log (d b h)
$$

Crown depth (V)

$$
V=\omega_{j} . H
$$

As left, where:

$$
\omega_{j}=\left(1-T_{j}\right) \cdot C_{0}\left(\omega_{j}\right)+T_{j} \cdot C_{1}\left(\omega_{j}\right)
$$

Maximum radius

As left, where:

$\left(\mathrm{R}_{\max }\right)$

$$
R_{\max }=r_{0, j}+\frac{d b h}{40} \cdot\left(r_{40, j}-r_{0, j}\right)
$$

$$
\begin{aligned}
& r_{0, j}=\left(1-T_{j}\right) \cdot C_{0}\left(r_{0}\right)+T_{j} \cdot C_{1}\left(r_{0}\right) \\
& r_{40, j}=\left(1-T_{j}\right) \cdot C_{0}\left(r_{40}\right)+ \\
& T_{j} \cdot C_{1}\left(r_{40}\right)
\end{aligned}
$$

Radius at height $h$ $\left(\mathrm{R}_{\mathrm{h}}\right)$

$$
R_{h}=R_{\max } \cdot\left(\frac{H-h}{H}\right)^{\beta_{j}}
$$

As left, where:

$$
\beta_{j}=\left(1-T_{j}\right) \cdot C_{0}(\beta)+T_{j} \cdot C_{1}(\beta)
$$

Crown area at height $\mathrm{h}\left(\mathrm{CA}_{h}\right)$

$$
C A_{h}=\pi \cdot R_{h}^{2}
$$

As left. 
814 The parameter values for the original allometries are given in Table S.2 for the species which

815 were included in the analysis. The broadleaf and conifer parameters were derived by re-fitting

816 the allometric relationships to simulated data which were weighted according to the relative

817 abundance of all of the species represented by these two allometries. The simulated data were

818 retrieved by using the height and maximum radius allometries from Table S.1 for each of the

819 included species to predict data points for a range of dbh measures where the number for each

820 species is proportional to the measured abundance. The allometries were then re-fit to the

821 simulated data to retrieve the parameter values for the conifer and broadleaf allometries.

822

823

824

825

826

827

828

829

830

831

832

833

834 
Table S.2 The species-specific parameter values for the allometric equations used to predict canopy structure from dbh measures with the lower then upper confidence intervals listed below in italics (where available). The * entries denote that the parameter values have not been directly extracted from the paper, but are derived from re-fitting the allometric relationships to simulated data weighted according to abundance of all included species. The ${ }^{\#} \boldsymbol{\varpi}_{\mathbf{j}}$ values for balsam fir and white spruce were calculated from unpublished data.

\begin{tabular}{|c|c|c|c|c|c|c|c|c|c|}
\hline \multirow{2}{*}{ Species (j) } & \multicolumn{4}{|c|}{ Caspersen et al. (2011) } & \multicolumn{5}{|c|}{ Purves et al. (2007) } \\
\hline & $\eta_{j}$ & $\phi_{j}$ & $\varpi_{j}$ & $r_{0, j}$ & $r_{40, j}$ & $\beta_{j}$ & $a_{j}$ & $b_{j}$ & $T_{j}$ \\
\hline $\begin{array}{l}\text { American } \\
\text { beech }\end{array}$ & $\begin{array}{l}23.8095 \\
23.6162 \\
24.0130\end{array}$ & $\begin{array}{l}.2967 \\
.2835 \\
.3143\end{array}$ & $\begin{array}{l}0.4749 \\
0.4721 \\
0.4772\end{array}$ & $\begin{array}{l}2.41848 \\
2.31153 \\
2.54481\end{array}$ & $\begin{array}{l}9.0831 \\
8.87821 \\
9.18623\end{array}$ & $\begin{array}{l}1.04203 \\
1.01849 \\
1.06318\end{array}$ & - & - & - \\
\hline Balsam fir & - & - & $\begin{array}{c}0.4512 \\
- \\
-\end{array}$ & - & - & - & $\begin{array}{c}0.1203 \\
- \\
-\end{array}$ & $\begin{array}{c}0.783 \\
- \\
-\end{array}$ & $\begin{array}{l}0.278 \\
0.276 \\
0.286\end{array}$ \\
\hline Hemlock & $\begin{array}{l}26.9651 \\
25.8911 \\
27.8909 \\
19.0506\end{array}$ & $\begin{array}{l}.7293 \\
.7104 \\
.7550 \\
1.572\end{array}$ & $\begin{array}{l}0.5240 \\
0.5186 \\
0.5318\end{array}$ & $\begin{array}{l}1.55475 \\
1.32560 \\
1.82560 \\
1.44703\end{array}$ & $\begin{array}{l}8.24872 \\
8.01792 \\
8.49993 \\
5.48292\end{array}$ & $\begin{array}{l}1.33787 \\
1.28702 \\
1.37687 \\
0.3837\end{array}$ & - & - & - \\
\hline Ironwood & $\begin{array}{l}18.6261 \\
19.4916 \\
20.9017\end{array}$ & $\begin{array}{l}7.5371 \\
1.6020\end{array}$ & $\begin{array}{l}14335 \\
.4438\end{array}$ & $\begin{array}{l}1.3658 \\
1.5305 \\
1.0439\end{array}$ & $\begin{array}{l}5.30517 \\
5.67222 \\
4.03818\end{array}$ & $\begin{array}{c}0.36194 \\
0.41123 \\
0.0001\end{array}$ & - & - & - \\
\hline Red maple & $\begin{array}{l}20.2315 \\
21.4944 \\
25.3588\end{array}$ & $\begin{array}{l}1.5688 \\
.772 \pi\end{array}$ & $\begin{array}{l}.4033 \\
.4167\end{array}$ & $\begin{array}{l}0.88105 \\
1.15198 \\
1.52529\end{array}$ & $\begin{array}{l}3.92248 \\
4.15271 \\
4.94851\end{array}$ & $\begin{array}{l}0.0001 \\
0.0001 \\
0.22977\end{array}$ & - & - & - \\
\hline Sugar maple & $\begin{array}{l}25.2651 \\
25.4421\end{array}$ & $\begin{array}{l}1.3440 \\
.354 \pi\end{array}$ & $\begin{array}{l}0.4596 \\
0.4619\end{array}$ & $\begin{array}{l}1.50483 \\
1.55158\end{array}$ & $\begin{array}{l}4.91789 \\
4.97733\end{array}$ & $\begin{array}{l}0.22255 \\
0.23762\end{array}$ & - & - & - \\
\hline White spruce & - & - & $\begin{array}{c}0.5889 \\
- \\
-\end{array}$ & - & - & - & $\begin{array}{c}0.1404 \\
- \\
-\end{array}$ & $\begin{array}{c}0.7354 \\
- \\
-\end{array}$ & $\begin{array}{l}0.278 \\
0.272 \\
0.296\end{array}$ \\
\hline Yellow birch & $\begin{array}{l}24.7702 \\
24.3362\end{array}$ & 1.1943 & $\begin{array}{l}0.4554 \\
0.4501\end{array}$ & $\begin{array}{l}4.1811 \\
3.92218\end{array}$ & $\begin{array}{l}8.09932 \\
7.79143\end{array}$ & $\begin{array}{l}1.03778 \\
0.98285\end{array}$ & - & - & \\
\hline
\end{tabular}




\begin{tabular}{|c|c|c|c|c|c|c|c|c|c|}
\hline & & & 0.4479 & & & & 0.4383 & 0.5564 & 0.5585 \\
\hline \multirow[t]{3}{*}{ Broadleaf* } & - & - & - & - & - & - & - & - & - \\
\hline & & & - & & & & - & - & - \\
\hline & & & 0.5213 & & & & 0.1939 & 0.7005 & 0.2618 \\
\hline \multirow[t]{2}{*}{ Conifer* } & - & - & - & - & - & - & - & - & - \\
\hline & & & - & & & & - & - & - \\
\hline
\end{tabular}

838 The extra parameters required for the Purves et al. (2007) allometries, which are not species

839 specific, are given in Table S.3 and were not altered. These parameters are used to transform the

840 Purves et al. (2007) species-specific parameters into the same form as those used directly in the

841 Caspersen et al. (2011) allometries.

Table S.3 The parameter values used to convert the species-specific trait score $T_{j}$ value into parameters describing the properties of the crown.

\begin{tabular}{lccc}
\hline \multicolumn{1}{c}{ Definition } & Parameter $(\mathbf{P})$ & $\boldsymbol{C}_{\mathbf{0}}(\boldsymbol{P})$ & $\boldsymbol{C}_{\mathbf{1}}(\boldsymbol{P})$ \\
\hline Crown depth & $\varpi$ & 0.95 & 0.95 \\
Crown radius at height 0 $\mathrm{m}$ & $r_{0}$ & 0.503 & 3.126 \\
$\begin{array}{l}\text { Crown radius at height 40 } \\
\mathrm{m}\end{array}$ & $r_{40}$ & 0.5 & 10.0 \\
Crown shape & $\beta$ & 0.196 & 0.511 \\
\hline
\end{tabular}

842 Definitions for all of the terms used in the model equations (eqs. 1-6) are detailed in Table S.4. 
Table S.4 Definitions of all symbols and terms used throughout the manuscript.

\begin{tabular}{|c|c|}
\hline Term & Interpretation \\
\hline SDD & Stem diameter distribution \\
\hline RMSE & Root mean square error \\
\hline DIC & Deviance information criterion \\
\hline $\mathrm{ABA}$ & Area-based approach \\
\hline ITD & Individual tree detection \\
\hline Dbh & Diameter at breast height \\
\hline Symbol & Interpretation \\
\hline HDLIDAR/ HDPREDICT & $\begin{array}{l}\text { Height distribution of LiDAR first returns in } 1 \mathrm{~m} \text { intervals } \\
\text { (recorded/predicted). }\end{array}$ \\
\hline$H D_{P R E D I C T}^{B A S I C}$ & Basic model. \\
\hline$H D_{P R E D I C T}^{P E R M}$ & Basic model incorporating crown permeability. \\
\hline $\begin{array}{l}\text { HD } \\
P E R E D I C T\end{array}$ & Basic model incorporating crown permeability and overlap. \\
\hline$H D_{P R E D I C T}^{F U L L}$ & Basic model incorporating all of the features - full model. \\
\hline$h / i$ & Vertical distance in metres above the ground. \\
\hline$h_{\max }$ & $\begin{array}{l}\text { Maximum predicted height of the canopy rounded up to the nearest } \\
\text { meter. }\end{array}$ \\
\hline$E C A_{[h, h+1)}$ & $\begin{array}{l}\text { Exposed canopy area in the height interval from, and including, } \\
\text { height } h \text { and up to, but not including, height } h+1\end{array}$ \\
\hline
\end{tabular}




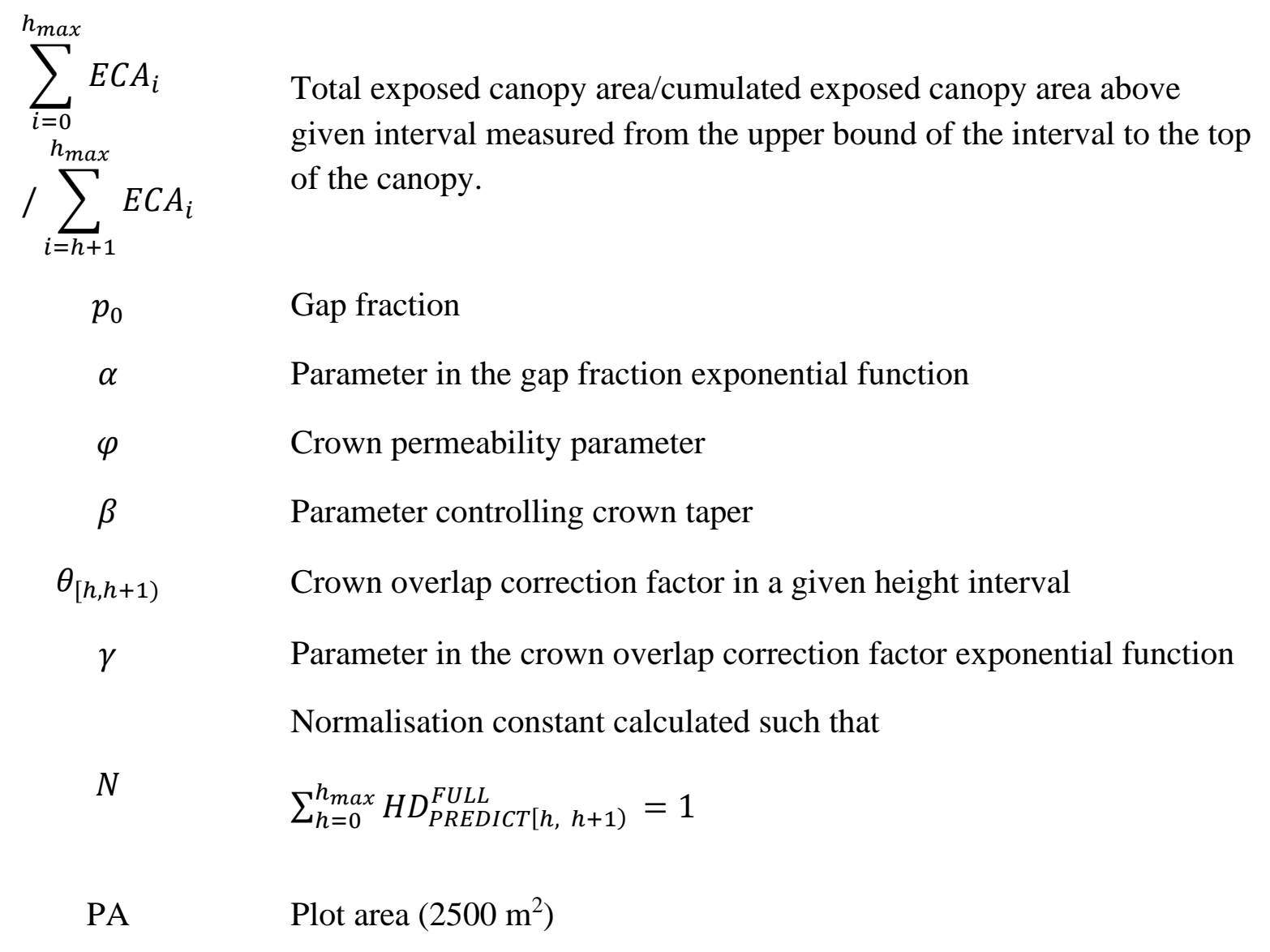

854 Model fitting results

855 The full model includes all features and is represented by eq. 6, but all of the features were tested

856 independently as well. The resultant fitted parameters used in the different model versions are

857 presented in Table S.5 along with the 95\% confidence intervals for each value.

858 To fit the new crown shape parameters $\left(\beta_{j, n e w}\right)$, we recalculated the maximum crown

859 radius $\left(R_{\max , \text { new }}\right)$ as follows:

860

$$
R_{\text {max }, \text { new }}=R_{\max }\left(\frac{H-V}{H}\right)^{\beta_{j}-\beta_{j, n e w}}
$$

The recalculated maximum crown radius and the new crown shape parameter can be used 862 in place of the original maximum crown radius and crown shape parameter.

863 The root mean square error (RMSE) was calculated as follows: 
864

(S. 2)

$$
R M S E=\sqrt{\left.\frac{\sum_{h=0}^{h_{\max }}\left(H D_{P R E D I C T}[h, h+1)-H D_{L I D A R}[h, h+1)\right.}{h_{\max }}\right)^{2}}
$$

865

Where $h_{\max }$ is the maximum predicted height of the canopy rounded up to the nearest

866 meter. The relative RMSE is calculated as:

867 (S. 3)

$$
\% R M S E=\frac{R M S E}{h_{\max }}
$$

Table S.5 Parameter values fitted using the LiDAR data from the model-fitting subset of plots.

The values in normal text are from the full model whilst those in italics are from the model independently representing that specific feature. The fitted values are presented with the

\begin{tabular}{|c|c|c|c|c|c|}
\hline Model version & Species (j) & $\begin{array}{l}\text { No. crown } \\
\text { allometries }\end{array}$ & Fitted value & Lower $95 \% \mathrm{CI}$ & Upper $95 \%$ CI \\
\hline \multirow{9}{*}{$\begin{array}{l}\text { Gap fraction } \\
\qquad(\boldsymbol{\alpha})\end{array}$} & & 1 & $2.3056(1.8560)$ & $2.2250(1.7935)$ & $2.3855(1.9183)$ \\
\hline & - & 2 & $2.7709(2.3458)$ & $2.6938(2.2787)$ & $2.8538(2.4109)$ \\
\hline & & 10 & $2.5618(2.2073)$ & $2.4917(2.1435)$ & $2.6362(2.2828)$ \\
\hline & & 1 & $0.4385(0.3650)$ & $0.4187(0.3541)$ & $0.4600(0.3783)$ \\
\hline & Sugar maple & 2 & $0.4320(0.3008)$ & $0.4126(0.2842)$ & $0.4542(0.3154)$ \\
\hline & & 10 & $0.3312(0.2323)$ & $0.3025(0.2166)$ & $0.3521(0.2500)$ \\
\hline & Conifor & 2 & $0.4910(0.3588)$ & $0.4145(0.2952)$ & $0.5798(0.4046)$ \\
\hline & comiler & 10 & $0.3850(0.1943)$ & $0.1919(0.0373)$ & $0.7585(0.3487)$ \\
\hline & $\begin{array}{c}\text { American } \\
\text { beech }\end{array}$ & 10 & $0.2565(0.1513)$ & $0.2116(0.1245)$ & $0.3055(0.1817)$ \\
\hline \multirow[t]{7}{*}{ Crown taper } & Balsam fir & 10 & $0.9390(0.5083)$ & $0.6147(0.3700)$ & $0.3055(0.6444)$ \\
\hline & Hemlock & 10 & $0.3613(0.2518)$ & $0.3155(0.2229)$ & $0.4017(0.2751)$ \\
\hline & Ironwood & 10 & $1.0711(0.0087)$ & $0.0045(0.0012)$ & $1.4855(0.0324)$ \\
\hline & Red maple & 10 & $0.4823(0.3257)$ & $0.4233(0.2962)$ & $0.5429(0.3621)$ \\
\hline & White spruce & 10 & $0.2045(0.1064)$ & $0.0900(0.0429)$ & $0.3366(0.1813)$ \\
\hline & Yellow birch & 10 & $0.2544(0.1638)$ & $0.2007(0.1234)$ & $0.3394(0.2207)$ \\
\hline & Broadleaf & 10 & $0.4213(0.3354)$ & $0.3656(0.2754)$ & $0.4753(0.3687)$ \\
\hline
\end{tabular}
associated $95 \%$ confidence intervals. 


\begin{tabular}{|c|c|c|c|c|c|}
\hline \multirow{3}{*}{$\begin{array}{c}\text { Crown } \\
\text { permeability } \\
(\boldsymbol{\varphi})\end{array}$} & \multirow{3}{*}{-} & 1 & $0.9334(0.6307)$ & $0.8548(0.6010)$ & $0.9924(0.6704)$ \\
\hline & & 2 & $0.8097(0.6557)$ & $0.6835(0.6049)$ & $0.9055(0.6930)$ \\
\hline & & 10 & $0.6507(0.6635)$ & $0.5575(0.6313)$ & $0.7351(0.6886)$ \\
\hline \multirow{3}{*}{$\begin{array}{c}\text { Crown } \\
\text { overlap }(\boldsymbol{\gamma})\end{array}$} & \multirow{3}{*}{-} & 1 & $0.3349(0.0004)$ & $0.3013(0.0001)$ & $0.3707(0.0012)$ \\
\hline & & 2 & $0.6092(0.0006)$ & $0.5606(0.0001)$ & $0.6693(0.0022)$ \\
\hline & & 10 & $0.5854(0.0004)$ & $0.5168(0.0001)$ & $0.6556(0.0012)$ \\
\hline
\end{tabular}

868 What would the accuracy of the approach be in matching LiDAR distributions?

869 Our planned approach to mapping SDDs is to use the model to generate an HDPREDICT for a huge 870 number of theoretical plots so that for each HDLIDAR we can identify a set of SDDs which have

871 similar HD

872 just a few similar-looking SDDs then it has worked well, whereas if a large number of dissimilar

873 SDDs are identified then the procedure does not have the ability to discriminate alternative size

874 structures with confidence without the use of additional information. This issue will be

875 thoroughly analysed in another paper, but as a preliminary test we matched the HDLIDAR of each

876 model plot with that of all the other model plots and measured the RMSE of each pairing (Fig.

877 S.1); this quantifies how many plots might be matched to a given HD LIDAR.

878

879

880

881

882

883

884

885 

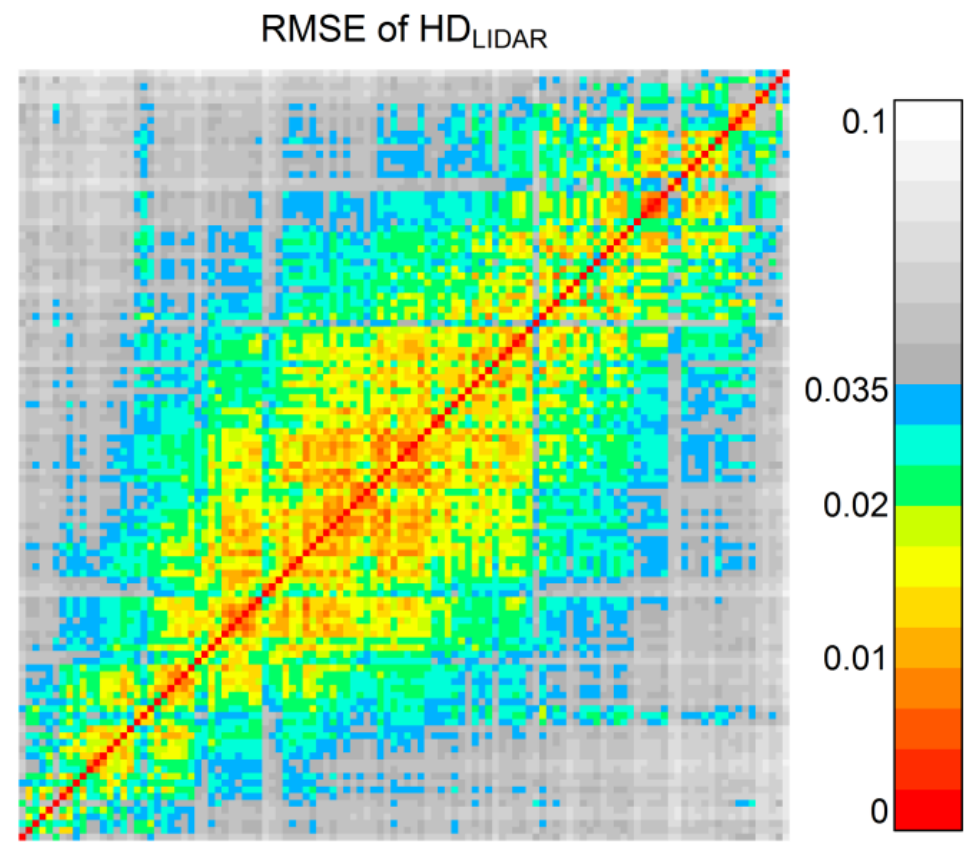

Fig. S.1 The matrix give the RMSE of each model plot $\mathrm{HD}_{\mathrm{LIDAR}}$ matched with that of each of the other model plots where the diagonal line is where the plot has been matched with itself. The plots have been ordered so that those with similar HDLIDAR distributions have been grouped together. The grey region are the matched plots with a RMSE less than the lowest RMSE achieved by the ten allometry full model, the blue-green region is the lowest RMSE to mean RMSE and the yellow-red region denotes all of the plots that match with a RMSE equal to or greater than the mean RMSE.

886 Given the accuracy of the ten allometry full model, $20 \%$ of the plots, on average, could be 887 matched as having the same HDLIDAR (Fig. S.1); these are denoted by the yellow-red region of 888 the matrix. 